\title{
How persistent is private equity performance? Evidence from deal-level data'
}

\author{
Reiner Braun ${ }^{\mathrm{a}}$, Tim Jenkinson ${ }^{\mathrm{b} *}$, Ingo Stoff ${ }^{\mathrm{a}}$ \\ ${ }^{a}$ Technical University Munich, Germany \\ ${ }^{b}$ University of Oxford, UK
}

\begin{abstract}
The persistence of returns is a critical issue for investors in their choice of private equity managers. In this paper we analyse buyout performance persistence in new ways, using a unique database containing cash-flow data on 13,523 portfolio company investments by 865 buyout funds. We focus on unique realized deals and find that persistence of fund managers has substantially declined as the private equity sector has matured and become more competitive. Private equity has, therefore, largely conformed to the pattern found in most other asset classes in which past performance is a poor predictor of the future.
\end{abstract}

This version, December 2015

JEL classification:

G11

G23

Keywords:

Private equity

Returns

Performance persistence

Portfolio companies

\footnotetext{
- We are grateful to Ludovic Phalippou, Tarun Ramadorai, Maximilian Schmidt, Berk Sensoy, Ayako Yasuda, Juergen Braun and participants at the 2012 Private Equity Research Consortium conference at University of North Carolina, the 2013 Stanford/JOIM Private Equity conference, the 2013 Finance Roundtable at University of North Carolina, the 2013 Business Research Seminar at the University Trier and the 2014 Private Equity Findings Symposium, London Business School, for helpful comments. We are particularly grateful to the anonymous referee whose comments and suggestions significantly improved the paper.

* Corresponding author at: Said Business School, Oxford University, Park End Street, Oxford OX1 1HP, U.K. Tel: +44 1865 288916; fax: +44 1865278820

E-mail address: tim.jenkinson@sbs.ox.ac.uk (T. Jenkinson)
} 


\section{Introduction}

Persistent out-performance by financial intermediaries is rare. Although such claims are often heard, academic research across asset classes has generally found past performance to be a poor predictor of future returns. An asset class where the claims of persistence have, to date, withstood academic scrutiny is private equity (PE) - including both venture capital (VC) and buyouts (Kaplan and Schoar, 2005; Lerner, Schoar and Wongsunwai, 2007; Hochberg, Ljungqvist and Vissing-Jorgensen, 2014). In this paper, we re-visit the issue of persistence of PE returns taking advantage of a new, extensive, deal-level data set of buyout fund investments, which allows us to overcome several limitations imposed by the standard fund-level data, and to propose alternative ways of analysing performance persistence in PE.

The analysis of performance persistence in PE faces several conceptual and data-related challenges, in comparison to more liquid and more transparent asset classes. The first conceptual issue relates to the fact that PE investments are typically organised into limited partnership funds, so that most analyses of returns consider performance persistence across successive funds of a particular PE manager (the General Partner, or GP). Funds have lives that are often in excess of ten years, reflecting the time taken to acquire, work with, and exit the portfolio companies (Metrick and Yasuda, 2010). Ultimate performance is only known accurately at the point when all investments have been exited, but the speed with which funds enter and liquidate their positions varies considerably. Until exit, funds report their estimates of asset values, but evidence suggests these are biased predictors of future cash returns (Jenkinson, Sousa and Stucke, 2013; Barber and Yasuda, 2014; Brown, Gredil and Kaplan, 2015). Therefore, reliance on fund-level data results in PE persistence being measured at a very low frequency, with a significant lag, and with data that - to the extent that there are unrealised investments - may be biased.

Second, GPs typically start to raise a new fund every two to five years into the life of the current fund (Gompers and Lerner, 2000). The overlapping structure of successive funds will create correlations in returns, due to exposure to common macroeconomic and financial conditions (Phalippou, 2010; Korteweg and Sorenson, 2014). Furthermore, some portfolio company investments are split between successive funds, which will induce spurious patterns of performance persistence between funds. These characteristics of PE are likely to result in an upward bias when measuring performance persistence at the fund level. 
Third, it is common for performance to be measured relative to other GPs, using metrics such as the internal rate of return (IRR), multiple of invested capital (MOIC) or public market equivalent (PME) returns (Kaplan and Schoar, 2005; Harris, Jenkinson and Kaplan, 2014, 2015). When benchmarking in this way it is essential to control for the dates of fund investments, as market conditions vary significantly over time. However, the distribution of investments over the life of the fund is not normally known to researchers, and so there is little alternative but to adopt the industry practice of using the reported "vintage year" of the fund. ${ }^{1}$ This poses a problem, as two funds with the same reported vintage year can invest their committed capital at a very different pace. Using fund-level data therefore introduces significant noise into the benchmarking process, which deal-level data can overcome.

Besides these conceptual issues, data availability of PE fund returns also remains challenging for analysing PE performance persistence. Even though better fund performance databases have become available, they typically do not have information on each fund of a particular manager. Consequently, there are often gaps in the fund sequences which complicate temporal comparisons of performance. Furthermore, recent research has raised serious questions about the reliability of some of the fund data that had been made available to researchers and was utilized in early studies. $^{2}$ For all these reasons, analyses of performance across funds are far from straightforward for both academics and investors.

In this paper, we are able to address these conceptual and data-related issues as we have timed cash-flow data at the deal-level for 13,523 investments made by 865 buyout funds run by 269 GPs. Funds, after all, are simply a legal wrapper around a sequence of underlying investments. For example, Blackstone Group is the GP of multiple funds. If one looks at the Blackstone website they provide considerable information on the companies in which they have invested over the years, but make little mention of which legal fund(s) made the investment. Our data

\footnotetext{
${ }^{1}$ Vintage years are, in practice, defined in various ways: common definitions include the date of the first investment, the final closing of the fund, and the first closing of the fund. GPs often declare a "first closing" when they have raised their minimum target. At this point they can start making investments. However, they would then continue fundraising, often announcing second or third closings, before declaring a final close of the fund. Different data providers use different definitions of vintage year, which creates opportunities for GPs to game their choice of definition to their advantage. See Harris, Jenkinson and Stucke (2012).

${ }^{2}$ In particular, Stucke (2011) finds that a significant proportion of the data in the Thomson Venture Economics data set is not being updated. These data were used by Kaplan and Schoar (2005) and Phalippou and Gottschalg (2009). The issues of data reliability for PE are discussed in more detail in Harris, Jenkinson and Stucke (2012) and Brown et al. (2015).
} 
allows an analysis of performance persistence of GPs through this lens: by stripping off the legal fund wrappers and considering how performance evolves across the deals undertaken by each GP, rather than limit the focus to comparing successive funds. The investments in our sample are split roughly equally between the U.S. and Europe, with a few in other regions, and span the period 1974 to 2012. For those investments that have not been fully exited we also have the latest net asset values (NAVs), although in this paper we largely focus on realized deals. The fact that we have timed cash-flows enables us to compute more relevant measures of performance, in particular PMEs, rather than being limited to reported IRRs and MOICs.

The structure of this data set is a major advantage for analysing PE performance persistence. As well as being extensive and detailed, for the vast majority of the GPs in our sample we have their complete investment history. This is clearly critical when analysing performance persistence, and lack of completeness is a problem that has plagued earlier analyses. We source the data from three fund-of-fund managers who required all GPs who sought capital to provide this detailed deal-level information in a standardized format. Importantly, the sample includes all the GPs upon which the fund-of-fund managers performed due diligence, whether or not they actually chose to invest.

Besides the completeness of the data set, our analysis also benefits from the availability of gross returns before management fees and profit shares (i.e., carried interest). Clearly, investors are ultimately interested in the net returns they earn. Harris, Jenkinson and Kaplan $(2014,2015)$ provide such evidence for the asset class as a whole. However, to understand the overall value creation of a GP, gross returns are a conceptually clean measure, since fund terms differ and will impact on the reported net returns at the fund-level. Even if fund terms were the same, the net performance of high-performing funds will be attenuated as the GP accrues, and then receives, carried interest payments, and this will impact on any analysis of performance persistence across funds using net returns (Berk and Green, 2004). Therefore, the ideal data for analysing performance persistence are precisely the deal-level gross returns, based on observed cash-flows, that we employ in this paper.

We start the analysis of performance persistence from the traditional fund perspective and repeat an analysis of the seminal paper by Kaplan and Schoar (2005), hereafter KS. We put each fund into a performance tercile, using the gross PMEs and the reported vintage year for each 
fund, and calculate the Markov transition probabilities for the subsequent fund. ${ }^{3}$ For the sample as a whole (including VC and buyout funds, with vintage years up to the late 1990s) KS found noticeable top-tercile persistence. Including VC funds with vintage years up to 1995, Phalippou (2010) confirms this pattern and finds a strong relationship between the final performance of two subsequent funds by the same GP. However, for our much larger sample of buyout funds, which includes both early and more recent funds, we find that performance persistence is noticeably lower. It is worth noting, however, that the earlier study by KS is based on data that included a majority of VC funds (as is Phalippou, 2010) and all funds were US-focussed. In contrast, our data is for buyout funds only, but is not restricted by geography. In the period since the late 1990s, buyout funds have come to dominate the PE market, and today constitute over $80 \%$ of capital raised.

In the remainder of the paper we explore whether the finding of reduced persistence remains when we analyse performance at the deal-level. The richness of our data allows us to produce new and cleaner analyses of performance persistence. ${ }^{4} \mathrm{We}$ focus on the fully realized investments in our sample, thereby avoiding any accounting valuation issues for the unrealised portfolio company investments. We also avoid the problem of deals that are split across one or more funds, so that only realized and unique buyout transactions remain in our sample. Since we have the timed cash-flows for each deal, we are able to benchmark performance accurately against deals being done at a similar time and to produce more meaningful measures of performance such as PMEs. Our main results are as follows.

First, we analyse the short-run persistence of returns across successive deals using a regression framework. This allows us to measure returns after controlling for the timing of deals, sectoral choices and region. However, choices over when and where to invest are also choices made by the GP, and so by including fixed effects the performance of a GP is purged of the impact of these choices, whether good or bad. Since we are also interested in absolute performance

\footnotetext{
${ }^{3}$ The approach of analysing performance persistence in PE based on Markov transition matrices is common among academic researchers (see Kaplan and Schoar, 2005; Chung, 2012; Harris et al., 2013) and industry practitioners. Results based on IRR and MOIC - as favoured by many in the PE sector - are available in the Internet Appendix to this paper, and show similar results.

${ }^{4}$ An interesting recent paper that also advances the analysis of performance persistence is Korteweg and Sorensen (2014), who develop a variance decomposition model based on a Bayesian procedure. They employ Preqin data, which only includes fund-level reported returns. Consequently, they focus on reported fund IRRs, as timed cash-flow data (even at the fund level) are not available.
} 
persistence across GPs we also run some regressions without controlling for sector, region, and investment timing. However, the results we find are consistent across specifications. For the whole sample we find that returns on the current deal are positively related to returns on the previous deal from the same GP. As an alternative to analysing successive deals we test whether, in the panel of deals, GP fixed effects are significant. In the overall sample, we find that returns are, in general, related at the GP level.

Second, we analyse whether this persistence has been changing over time. We partition the data sample into an early period up to the end of 2000, which is broadly in line with the original KS fund-level sample period, and a later period from 2001 onwards. ${ }^{5}$ Our deal-level analyses find that performance persistence has largely disappeared in recent years. This is consistent with the PE sector maturing, with financial engineering and valuation techniques becoming commoditized, professionals moving between or forming new GPs, and the ways to create operational improvements to portfolio companies becoming assimilated across firms. Furthermore, whilst "proprietary deals" - where a GP is able to invest without competition from rivals - are still common in the $\mathrm{VC}$ sector, they have largely given way to auctions (run by investment banks) in the buyout sector (Braun, Crain and Gerl, 2015).

Third, we consider whether falling persistence is due simply to the PE market maturing with the passage of time, or whether persistence is also related to competition for deals. We develop a proxy for the extent of money-chasing-deals (Gompers and Lerner, 2000) by region and sector, and analyse whether GP performance becomes more or less persistent depending on the state of competition. By our measure, competition has clearly increased in recent years, but not evenly over time or by region. We split the sample of deals into those conducted in periods of high and low competition, and repeat the earlier analysis. Controlling for time, we find that the competitive state of the market also impacts on performance persistence: when a large amount of capital chases deals, persistence tends to be lower.

Our fourth set of results focuses on the top performing funds, since it could be that there is considerable variation in the returns of most fund managers, but that an elite group of GPs produces consistently good returns. After all, the claims that are typically heard from GPs are of

\footnotetext{
${ }^{5}$ Kaplan and Schoar (2005) included funds that were largely liquidated at the time of their analysis, which in practice meant funds with vintage years up to around 1996. Such funds could continue making investments until around 2000 .
} 
persistent top-quartile returns, rather than, for example, persistently average performance. By looking at the returns across all GPs we may mix the random with the persistent. We sort deals into performance quartiles for each year based on their PME. We then run logistical regressions to estimate the probability of subsequent deals also being in the top quartile. We find significant evidence of top quartile performance persistence in low competition states but much less so when competition is high. We also run a similar analysis for the bottom quartile of deals, and, interestingly find that GPs who do bad deals tend to repeat, irrespective of the state of competition. Indeed, much of the remaining persistence in PE returns in high competition states is associated with the worst deals.

Finally, we also look at the longer-term persistence of returns, using the approach employed by Carhart (1997) in his analysis of mutual fund managers. We sort deals into performance quartiles and then track the subsequent 10 deals by each GP. This analysis confirms that most of the performance persistence is in the top and bottom quartiles. For the top quartile, deal-level performance is more persistent and long-lived in periods of low competition. In high competition periods, the performance differences are marginal and do not persist beyond the subsequent few deals. However, poorly skilled GPs consistently underperform, irrespective of the state of competition. This finding of bottom-quartile persistence clearly raises interesting questions as to why investors continue to fund such GPs.

Overall, the evidence we present suggests that performance persistence has largely disappeared as the PE market has matured and become more competitive. Our findings may help to explain similar results about the ability of limited partners (LPs) to consistently produce superior relative returns. Sensoy, Wang and Weisbach (2014) find that LP performance persistence has disappeared in recent years. The disappearing GP and LP persistence may plausibly be linked. Those LPs who were early investors in PE - such as endowments established relationships with successful GPs which were valuable when the market was developing. However, those relationships, and access to funds - at least on the buyout side - are now much less valuable and are no longer a source of LP out-performance. Interestingly, Harris et al. (2013), using fund-level data, find continued performance persistence for the top VC funds (but not for buyout funds). It seems plausible that competitive forces are less strong in VC, where particular GPs have approaches, networks and brands that are much valued by entrepreneurs, leading to less commoditization and continued proprietary deal-flow. This stands in contrast to 
buyouts, where in both the U.S. and Europe most deals today are auctions run by investment banks, debt financing is highly competitive, deal structures vary little by GP, and vendors - who usually sell the entire company or at least a controlling stake - typically focus on the price paid rather than the reputation or the value-add of the GP.

The remainder of the paper is structured as follows. In the next section, we explain carefully our deal-level data, sample selection and benchmarking issues. In Section 3 we analyse performance persistence across the whole sample, by time and by competition level. In Section 4 we focus on the funds with the best, and worst, relative performance. Section 5 concludes.

\section{Data}

In this paper, we use an extensive data set of PE buyout investments. The data are derived from three large fund-of-fund $(\mathrm{FoF})$ managers as an integral part of their due diligence process when selecting PE funds to invest in. An important feature of the data set is that all GPs who sought capital from one or more of the FoF managers were required to provide information on all their prior fund investments. Therefore, if a GP sought capital, e.g. for its fifth fund, detailed information would be required on funds one to four. Of course, the FoF managers only chose to invest in a small fraction of the funds. Our data set comprises the full sample provided by all the GPs that manage buyout funds, and is in no way affected by the selections of the FoF managers.

\subsection{Funds and fund families}

The data from each FoF manager are merged and duplicate GPs are removed. In total, our sample includes 269 GPs and 865 buyout funds. Each time a GP approached a FoF manager their track records were updated. The latest updates therefore vary by GP, with the most recent being from 2013. For investments that had not been realized, the latest NAVs were provided. A small number of GPs run more than one "family" of buyout funds - usually distinguished by geographic area - and we treat these as distinct sequences of funds and deals since regionally focussed 'divisions' within one large GP organization may have different experience, networks, skills etc. These are the sort of attributes that we would expect to influence performance persistence. For the 269 GPs, 301 fund families are identified. An attractive feature of the data is that it is balanced between funds with their origin in the U.S. (421 funds) and Europe (394 funds). It also includes a limited number of funds from Asia (50 funds). Most previous academic 
studies have focused on U.S. funds only, whereas European PE transactions comprised $47 \%$ of global deals by value between 2000 and 2007 (Kaplan and Strömberg, 2009).

Details on the number of funds and families are provided in Table 1. Panel A shows that for $85 \%$ (256 out of 301) of the fund families, we have complete information back to the first fund. In most of the remaining cases the sequence is complete but does not go back to the first fund (as such detailed records were not always kept for early investments). We have gaps in the sequence for only six fund families. This completeness is a major strength of the data set, given our focus on performance persistence. No other data set that we are aware of combines a large number of funds with such a high level of completeness over the life of the GP/fund family. The completeness, and deal-level granularity, of our sample reflects the fact it was gathered from fund due diligences, rather than the actual holdings of investors. Balanced against these advantages, there are inevitable sample selection issues as GPs who disappear, maybe because of poor prior performance, may not be part of our data set. We address these selection issues first, before describing our sample.

\subsection{Sample selection issues}

There are broadly three ways to source data on PE - from investors' actual holdings of funds, from the funds themselves, or from those funds that sought investors. Each involves potential biases. Most analyses of PE returns have relied on data sourced from some combination of the first two - that is from the holdings of LPs or the returns reported by GPs. Harris, Jenkinson and Stucke (2012) discuss the main sources of PE data. For any data source that relies on GPs to reveal their returns, biases are likely to arise from the lower probability of revealing the past performance of funds that performed poorly. Similarly, to the extent that data from GPs is backfilled, there will be survivorship biases.

Consequently, LP-sourced data has many attractions. A number of papers, such as Ljungqvist and Richardson (2003) and Robinson and Sensoy (2013) source return data from single large LPs. However, such data inevitably raise questions about whether the particular investor was representative in its choices and/or success. Data sourced from multiple investors is likely to be the most representative, such as that used by Harris, Jenkinson and Kaplan $(2014,2015)$ and Harris et al. (2013), who use Burgiss data, sourced from over 200 institutional investors. Such data is unlikely to suffer any major biases, but will inevitably have gaps in the fund sequences, 
reflecting investors' choices about which funds to invest in. This is less important for analysis of PE returns, but is a serious constraint when analysing persistence.

Regarding our data, the completeness of the fund sequences is exceptional, reflecting the requirement imposed by the FoF managers for GPs to reveal all their past deals. However, there are two potential biases in our sample. First, not all funds will have sought capital from the three FoF managers. This would be a problem if funds with particular performance characteristics avoided our investors. This is a theoretical possibility, as some GPs may have a bias against having FoFs as investors (preferring direct relationships with the ultimate investors). However, it is worth remembering that this data was gathered in the course of fund due diligences over the last several years. The balance of power shifted significantly from the GPs to the LPs after the financial crisis. Many investors became over-allocated to PE and so ceased making new commitments. Consequently, fundraising became exceptionally challenging. Beggars can't be choosers, and so we doubt whether this potential bias is significant. This belief is reinforced by the fact that the average performance of our sample of funds is similar to that found in other studies.

Second, given the nature of our data, there will inevitably be some survivorship bias in the sample. Only GPs who sought capital from our FoF managers can be included in the sample. Consequently, GPs who had raised funds in the past (from other investors) but subsequently quit the sector will be excluded - although if they tried unsuccessfully to raise a fund, they could still appear in our sample. Little is known about the extent of attrition among GPs focused on buyouts. However, using Thomson Venture Economics (TVE) data, which was the only major databases to provide sequence numbers for fund families, we find that the extent of attrition amongst GPs is low. ${ }^{6}$ Using this data, we find that only one in twelve first-time GPs do not have a second fund in the database. Indeed, this will be an upper bound on the attrition rate, as no database, including TVE, will have complete coverage of funds raised. This suggests that the impact of survivorship bias should be limited in our data. ${ }^{7}$ Furthermore, given that the focus of

\footnotetext{
${ }^{6}$ We are grateful to the Private Equity Research Consortium for providing access to the data on the private equity universe, as described in Brown et al. (2012). The aim of this project is to estimate the total size of the private equity sector by merging and cleaning up the major commercial databases that track fundraising by GPs. We use the past tense to describe the TVE data as it is no longer commercially available (see also footnote 2 ).

${ }^{7}$ Conversations with practitioners confirm that few GPs disappear after only one fund. The reason for this is that at the time of raising a second fund most of the existing investments will be unrealized, and so poor (ultimate) performance may not be apparent. Consequently, funds may be able to raise two funds, but if performance on the
} 
this paper is on performance persistence, at the fund level we would only include those GPs in our sample with at least two funds. At the deal level we perform some robustness checks to exclude entirely the first few deals from all GPs (following the approach of Jagannathan et al., 2010, in their analysis of hedge fund performance persistence), and find only a minor impact on the results. Therefore, we believe the completeness and deal-level granularity of our data, and limited evidence of survivorship bias, makes it the most suitable buyout dataset yet assembled to study performance persistence.

\subsection{Funds}

Table 2 provides descriptives for our sample of 865 conventional buyout funds that made 13,523 portfolio investments. ${ }^{8}$ When sorting the funds by vintage year, the sample shows the high number of funds raised in the boom years from 1998 to 2000 and from 2005 to 2007. The sample exhibits a comprehensive coverage of fund vintages after 1989 and until 2008, whereas the number of funds drops thereafter. This pattern reflects the fact that our data represents the past history of GPs when they fundraise. The last update of the data was in 2013, and few GPs that had previously raised a fund after 2008 were seeking capital for their next fund by 2013 . The overall mean fund size of USD 1,045 million is comparable to Robinson and Sensoy (2013), whose mean fund size in their sample is USD 988 million. The mean fund generation number across the whole sample is 2.8. As might be expected, the average experience of GPs is increasing over time, even though new GPs are entering all the time.

Table 2 also presents gross fund returns by vintage year. An advantage of our data set is that it contains all monthly deal-level gross cash flows (before management and performance related fees) between the fund and the portfolio company as well as NAVs for all unrealized deals. ${ }^{9}$ This information enables us to calculate the exact gross PME and $\mathrm{MOIC}^{10}$ for each deal as well as for

first fund is disappointing, the GP finds it hard to raise a third fund. This lack of timely and reliable performance data at the point of fundraising may help to explain our finding that there is noticeable persistence among the worseperforming GPs - since if investors were able to judge relative performance reliably, such GPs should not have raised further funds.

${ }^{8}$ Achleitner, Braun and Engel (2011) and Braun et al. (2011) analysed initial versions of the data set.

9 We also have full deal-level information of the industry, country, realization status and investment date approximated by the first deal cash flow. For each fund family, we further know the fund type and its origin.

${ }^{10}$ We can, of course, also calculate IRRs for each deal, but we do not focus on this performance measure in the paper. IRRs are questionable as a performance measure and extreme positive values can occur, resulting in a highly skewed distribution. 
each fund after aggregating the cash flows at the fund-level. The mean (median) fund gross PMEs are 2.0 (1.8) and MOICs are 2.3 (2.0). ${ }^{11}$ Using the Stoff and Braun (2013) analysis of the relationship between gross and net fund returns, the mean net fund MOIC would be around 1.9. This is very similar to the net MOIC of 1.97 found by Harris et al. (2014), although they focused on U.S. buyouts, whereas U.S. funds comprise around one-half of our sample.

Table 2 also shows by vintage year the number of funds with a previous fund; we refer to two consecutive funds as a fund sequence. We are especially interested in this information given our focus of performance persistence over time. Our sample includes 564 fund sequences. In comparison, the early study by Kaplan and Schoar (2005) contains 76 buyout fund sequences, and Harris et al. (2013) contains 285 buyout fund sequences. Therefore, this study includes, by some considerable margin, the largest sample of consecutive buyout fund returns yet assembled, reflecting the completeness of the data noted earlier.

\subsection{Deal-level data}

As noted in the introduction, there are various challenges using fund-level data to study performance persistence. First, more recent funds will include a high proportion of unrealized deals, and the final performance of such funds can deviate considerably from that reported when many of the investments are unrealized. Restricting the sample to substantially realized funds (the approach taken by KS) will circumvent the issue but reduces the sample size considerably.

Since we have cash-flow (and NAV) data at the level of the individual deal, we are able to classify each investment according to whether it is fully realized, partially realized or unrealized. Table 2 shows that the mean total number of deals per fund ranges from 10-20 for most vintage years, and averages 15.6 over the entire sample. The relatively low total portfolio sizes reported for the vintage years after 2007 indicate that these funds have not yet finalized the investment phase when the most recent data was gathered. The realization status of the deals reveals some interesting findings, in particular the fact that on average even funds raised in the early 1990s still had some unrealized deals in 2013. This is consistent with the fact that many funds are extended considerably beyond their initial life of 10 years.

\footnotetext{
11 Throughout this paper, all performance measures at the fund and deal level are winsorized at the 99th percentile.
} 
Second, consecutive funds by the same GP often contain the same portfolio companies. This occurs in part because two consecutive funds, which are both in their investment phase, often have the right, or the obligation, to invest pari passu in the same deals. Table 2 shows how prevalent common deals are across funds managed by the same GP. On average across the sample there is one such deal per fund (or about $6.4 \%$ of all deals), which will induce some limited artificial persistence when comparing successive funds.

Third, although it is conventional to benchmark performance against funds of the same vintage year, this approach has various drawbacks. GPs can define a vintage year with a degree of leeway according to the first or final closing of a fund or the year the first company is acquired. ${ }^{12}$ Furthermore, even if two funds have reported the same fund vintage year, say 2007, they might face very different economic environments when putting capital to work. One of the funds might have needed more time to invest, for example until 2010, while the other fund might have invested a substantial share of its commitments before the financial crisis struck. The latter fund invested in a period characterized by peak transaction multiples. This is hardly comparable with the former fund's investment environment where assets were acquired at lower multiples in times of economic recession. This is a significant issue when benchmarking fund performance against peers with the same vintage year. We can avoid this issue entirely at the deal level as we know the date of each investment. Table 3 provides summary information on the median investment years of the 12,541 unique deals in our sample (excluding common deals), as well as their realization status, size, holding periods and returns ${ }^{13}$. Furthermore the distribution of the sample by time period, location of investment, sector and deal sequence number is presented. ${ }^{14}$

\section{Performance Persistence}

We start our analysis of performance persistence from the traditional fund-level approach, to compare how results derived from our data sample compare with those previously derived in the

\footnotetext{
12 See Harris, Jenkinson and Stucke (2012) for an analysis of how funds can, and do, strategically choose their vintage year to optimize their apparent performance relative to various industry benchmarks.

13 The difference in median returns between fund and deal level results from weighting the deals according to investment size when computing fund returns.

${ }^{14}$ When we are missing one or more funds in the sequence, we interpolate the deal sequence numbers using the median number of deals performed by the GP in the funds for which we have information.
} 
literature. We then focus on new ways of analysing performance persistence with the benefit of deal-level data.

\subsection{Comparison with previous fund-level research}

Relatively few prior papers have analysed PE performance persistence. The seminal work in this area is Kaplan and Schoar (2005) who examine a sample of funds with vintage years until the late 1990s using two main approaches. First, they sequence funds by GP and analyse within a regression framework whether the returns on a given fund depend on the returns on the previous fund. Returns are measured both in terms of PME and IRR. Second, they place each fund into a performance tercile by vintage year and analyse the Markov transition matrices to compute the probability that a GP stays in the same performance tercile in successive funds. For this latter exercise, buyout and VC funds are grouped together. Terciles, rather than quartiles, are used presumably due to data limitations, as only 398 funds had at least one follow-on fund, of which only $20 \%$ were buyout funds. Splitting the sample into 16 groups for quartiles would have resulted in some very sparsely populated cells in the matrix. Using this early sample of PE funds, and PME as the performance measure, KS find significant performance persistence: the probability of repeating top (bottom) tercile performance in successive funds is $55 \%$ (44\%), and the hypothesis of random transition probabilities across all the cells is rejected at the $1 \%$ level.

In Table 4 we re-produce the latter analysis for our sample of funds. We face the issue of unrealized deals and so only include funds where at least $50 \%$ of the capital invested has been realized. This is similar in spirit to the approach of KS, who focus on "substantially realized" funds; given our deal-level data we can set the cut-off precisely. We find that the probability of repeating top (bottom) tercile performance is lower in our sample: 39\% (40\%), and we can only reject the hypothesis of random transition probabilities at the $10 \%$ level. It is worth remembering, however, that our samples are quite different: we focus on buyout funds on a global basis, and $\mathrm{KS}$ analyse both buyout and VC funds but restrict the analysis to US funds. Furthermore, with the passage of time our dataset of buyout funds is much more extensive: 534 mature funds ${ }^{15}$ have at least one mature subsequent fund, whereas the comparable number of buyout funds in the dataset used by KS was 76. The difference in our results could emanate from the mixing of VC and

\footnotetext{
15 Thirty fund sequences are excluded by the requirement that at least $50 \%$ of the invested capital of any fund must be realized.
} 
buyout funds, or from geographical differences in persistence, or persistence may have changed over time as the PE sector has matured and grown.

Given that our data focuses entirely on buyout funds, we can say little about the possible differences between the performance persistence of $\mathrm{VC}$ and buyout funds. However, recent fundlevel research by Harris et al. (2013) shows that persistence of VC returns has remained virtually unchanged. This suggests that any changes in performance persistence may be focussed on buyout funds, and the remainder of this paper tests whether persistence has changed over time and disentangles the possible explanations.

\subsection{Deal-level persistence regressions}

Although Markov transition matrices have been widely used when analysing PE fund performance, the availability of deal-level data enables many alternative approaches. A key decision is the frequency with which to measure persistence. For instance, for mutual funds and hedge funds persistence is typically analysed by observing monthly or annual returns. However, changes in the reported value of a fund over its life would largely reflect the changes in the valuation of the portfolio companies produced by the GPs and their auditors, rather than market prices. Only once investments are realized are the returns known. Our approach in this paper is to sequence the investments made by the GP according to their date and then measure the persistence of performance across deals. This results in a much higher frequency measure of performance persistence than fund-level metrics. Clearly the significant idiosyncratic volatility in returns tend to be smoothed at the fund level, but any trends in performance should still be observable with a large enough sample of deals. Each deal can include controls for some sources of idiosyncratic variability, such as industry, geography, GP experience etc. We are also able to control much more precisely for the influence of market conditions and any other priced factors.

We start with a regression framework using the sample of 7,568 fully realized unique deals covering the period from 1979 to 2012, which we sequence by investment date. ${ }^{16}$ We focus on PME as the performance measure, as the returns on PE deals are highly correlated with market conditions. To begin with we simply regress a given deal's $\left(\mathrm{n}_{0}\right)$ return on the previous investment $\left(\mathrm{n}_{-1}\right)$ return by the same GP. We use the three regional MSCI total return indices (Asia, Europe, North America) in local currency as benchmarks for our PME calculations. The results are

\footnotetext{
${ }^{16}$ For this purpose we produce a sequence for each GP based only on realized deals.
} 
reported in Table 5, column 1. The coefficient on the lagged PME return is positive and statistically significant. ${ }^{17}$ In economic terms, the point estimate of 0.102 implies that a current deal with a $1 \%$ higher performance in the previous deal is associated with a 10.2 basis points better return.

To the extent that we attribute performance persistence to GP "skill", this baseline regression attributes any co-movement of two subsequent deals to the GP's skills. These skills could include picking the right industry, region, or appropriately timing the market. In order to examine more demanding views on performance persistence we run further regressions adding further information on the investment and the GP. To begin with, in column 2 we control for the deal sequence, the size of the equity investment, the holding period and fund age since the first investment. Controlling for deal sequence isolates the effect of GP experience on performance. By adding equity investment size we account for differences in returns across segments (say small, mid and large cap). If buyouts outperform (or underperform) the public market benchmark over time, a longer holding period should result in a higher (lower) absolute PME return. By including the holding period we account for differences in PME returns due to this effect. Interestingly, after including all these controls the coefficient on lagged performance is nearly unchanged.

In column 3 we also add controls for the deal's industry and region. Thereby, we no longer attribute GP skill to 'just' picking the right region or industry. The coefficient on lagged performance decreases slightly but remains statistically significant. In column 4 we add investment year fixed effects to the regression, and so performance persistence is measured relative to deals undertaken in the same period. As we add more controls, and thereby interpret GP skills in a more "relative" way - relative to deals done at the same time in the same sector and region - the correlation between the returns on successive deals reduces slightly, but remains significant. The coefficient of interest is 0.078 and indicates a 7.8 basis points association of current with previous deal performance. Therefore, in the overall sample there is evidence that GPs differ in their ability to pick or develop portfolio companies in a given segment of the buyout market.

\footnotetext{
17 Standard errors in all subsequent regressions in this paper are adjusted for heteroskedasticity and serial correlation.
} 
As outlined in Section 2.2, our sampling strategy might potentially result in a selection bias if poorly performing first-time funds never attempt to raise a subsequent fund, and so our sample of early deals may include too few poor performers. In order to test robustness of our findings, we re-run regression (4) but exclude the first ten investments by each GP, which is equal to the mean number of realized unique deals by first-time funds (9.9 investments) in our sample. The coefficient on lagged PME return is reduced to 0.063 and remains statistically significant.

Finally, in column 6 we address the persistence issue in a slightly more general way. Rather than measure persistence from one deal to the next, we test whether GPs vary systematically in their average performance over their entire sample of deals by including GP fixed effects, in the vein of Bertrand and Schoar (2003) assessing the effects of CEOs on firm performance. Testing joint significance of GP fixed effects yields a F-value of 2.228, which is statistically significant. This means that, in the overall sample, heterogeneity in performance across deals is explained to some extent by the identity of the GP.

As in all other regressions in Table 5, in column 6 we find that smaller investments outperform larger ones. A 50\% increase in equity investment is associated with 0.037 decline in PME. ${ }^{18}$ The significant negative coefficient on the log of deal sequence indicates that investment performance declines over a GP's life. In economic terms, it suggests that for each $50 \%$ increase in deal sequence the expected PME decreases by 4.4 basis points. The smaller coefficient on the $\log$ of deal sequence in model 5, excluding a GP's first ten deals, suggests that the decline in returns over a GP's life in our sample is driven by early investments. Finally, all coefficients on the log of the holding period in Table 5 are significant and positive. In the GP fixed effects model (column 6) a 50\% increase in the holding period is associated with a 7.3 basis points higher PME. The longer the maturity of the transaction the higher is the relative out-performance of the public benchmark. Finally, the fund age control, which is positive and significant (except when we include GP fixed effects) suggests that, ceteris paribus, the later deals in a fund mildly outperform the earlier deals.

\subsection{Has persistence changed over time?}

The multivariate regressions on the full sample in Table 5 indicate that there has been some degree of performance persistence in buyout returns over the last 35 years. However, has

\footnotetext{
$18-0.211 * \log (1.5)=-0.037$.
} 
persistence changed over time, as the market has matured? In order to explore, in Table 6 we rerun some of the regressions, but split the data into two subsamples: investments up to 2000 and those with later investment years. Assuming an average fund investment period of 5 to 6 years, the earlier period is roughly similar to that analysed by $\mathrm{KS}$ who include funds closed prior to 1996 for their persistence analysis (Kaplan and Schoar, 2005, p. 1806).

Column 1 shows that deal-by-deal performance persistence before 2001 was positive and statistically significant. In this basic regression, an $1 \%$ higher previous deal return (relative to public markets) is associated with a 11.9 basis points higher return in the next investment. When including all controls in column 2 (equivalent to regression 5 in Table 5) this effect is reduced to 9.5 basis points and remains statistically significant. This is much stronger than the effect in the later period covering deals from 2001 onwards. In the basic regression (column 4), the 4.7 basis point effect is weakly significant. Adding the controls in column 5 results in a statistically insignificant effect of only 2.2 basis points. These findings suggest that persistence in buyout returns has largely disappeared as the market has matured. This is confirmed by the GP fixed effects regressions using the two separate subsamples. The F-test of joint significance of the GP fixed effects is highly statistically significant in the early period of the PE market (column 3) but insignificant when focussing on deals since 2001 (column 6).

\subsection{Does competition reduce persistence?}

An interesting question that these results raise is whether we can identify the economic drivers behind this time trend. One observable candidate is the extent of competition. Other currently unobservable candidates include the assimilation of valuation and financing techniques across GPs, the number of proprietary deals (as opposed to auctions), movements of investment professional between GPs, etc., but these require data that does not currently exist. In order to obtain a proxy for the competition for each deal in our sample we compute a variable that measures 'money chasing deals' (Gompers and Lerner, 2000): the ratio of capital raised by buyout GPs to overall GPD.

Drawing on the data from the Private Equity Research Consortium (Brown et al., 2012) which consolidates the fundraising data from Burgiss, Preqin and Thomson to provide a measure of the 
size of the PE universe, we compute fundraising in a given buyout market segment. ${ }^{19} \mathrm{We}$ aggregate all fund sizes of buyout vehicles closed in a given year, in a given industry (ten ICB industries), and in a given region (North America, Europe, Asia or Rest of the World). For example, the total amount raised by buyout funds closed in North America in 2003 in the Health Care industry (ICB code: 4000) equals USD 4,560m. Rather than take a single year's fundraising data, we sum the capital raised in the three previous years in the same region and industry. This provides a more realistic picture on the actual demand for buyout deals as on average more than $50 \%$ of committed capital is invested in the first three years after fund closing (Ljungqvist and Richardson, 2003). This also has the benefit of smoothing out single years of extremely high or low fundraising. To account for the size of the economy, we divide this total buyout capital amount from the previous three years by the GDP in the current year at purchaser's prices in current USD using national data from the World Bank which we aggregate for the four regions.

The development of this competition proxy in the three main regions (aggregated over all industries in a year and region) is illustrated in Figure 2. While the graph indicates stronger competition in the North American PE market, it also illustrates a very similar time trend for North America and Europe. After a steady increase in competition until the millennium, there was a sharp decline after the dotcom bubble burst which lasted until the mid-2000s. Competition grew again to much higher levels until the financial crisis in 2008 terminated this trend. While being at a lower level, PE competition in Asia started to grow in the early 2000s and has not experienced a sharp decline but rather steady levels since the mid-2000s. We use this information to analyse performance persistence in different competition environments.

Table 7 repeats the analysis presented in Table 6, but splits the sample into deals executed in periods of above and below median competition. It is important to note that this competition dummy is not simply an artefact of time, and so is not almost perfectly correlated with our early/late periods. While the majority of high competition investments, according to our binary variable, were done in the more recent period after the year 2000, 617 realized investments (or $18 \%$ of all high competition deals) were undertaken in the early period of the PE market before

\footnotetext{
${ }^{19}$ See footnote 6 . We only consider fundraising by buyout funds. The various data providers classify funds in different ways but we consider funds to belong to the buyout asset class if they are either classified as buyout, generalist private equity, other private equity or later stage in Thomson; buyout, balanced, growth, generalist, later stage or other private equity/special situations in Preqin; or finally, as buyout in Burgiss.
} 
the millennium. In turn, 970 realized investments (or $23 \%$ of all low competition deals) were carried out in the later period.

The coefficients on lagged deal PME return in the basic regressions are statistically significant in the low (column 1) as well as in the high competition subsample (column 4). However, the coefficient on past performance in a low competition environment is almost three-times higher than that estimated in high competition environments. When including various controls in columns 2 and 5, respectively, this difference remains, and evidence of persistence in the high competition subsample is only weakly statistically significant.

We find a similar pattern when testing the difference in GP fixed effects. The F-value for the GP fixed effects in the low competition subsample reported in column 3 is highly statistically significant. While remaining significant, the F-value for fund manager fixed effects in the high competition environment falls by around a half.

Finally, we test the sensitivity of our results to introducing a "medium-competition" state. The reason for making this distinction is as follows. ${ }^{20}$ If, as seems plausible, money flows into the PE sector following high returns and fundraising is more difficult following poor returns, then this may result in a non-linear relation between persistence and our measure of competition. Returns may be low in high competition states, as too much money chases too few deals or as returns simply mean-revert. Similarly, future returns may be higher when fundraising has been low. So persistence may be low in both the high and low competition states. Persistence might be strongest in more stable "medium competition" states. To test this, we re-run the regressions for high, medium and low levels of competition, but find the same rather linear relationship: performance persistence is inversely related to competition across the three states. These regressions are available in the Internet Appendix.

\subsection{Does exposure to common risk factors explain the results?}

One might object that the results on performance persistence over time and competitive states of the buyout market may actually be driven by varying exposure to risk factors. As noted by Sorensen and Jagannathan (2015), PME adjusts for exposure to market risk and does not restrict the beta loading of each deal. Therefore, PME will control for certain important risks - in particular leverage, which is likely to vary with the credit cycle and may be correlated with

\footnotetext{
${ }^{20} \mathrm{We}$ are grateful to the referee for this suggestion.
} 
competition for deals. This is an important reason why PME is a much more suitable performance metric than absolute measures such as IRRs and money multiples.

However, whilst PME controls flexibly for exposure to market risk, other potential risk exposures exist. In order to test the robustness of our results we re-run our deal-level regressions using an extended version of the Generalized PME (GPME) approach of Korteweg and Nagel (2015) as the measure of performance. Although a generalization of the standard PME, the GPME has a different interpretation as it is the difference between discounted inflows and outflows from the asset (as in the NPV approach), whereas the Kaplan and Schoar (2005) PME is constructed as a ratio. The GPME is obtained by estimating investment-specific stochastic discount factors to appropriately determine the present values of cash flows. The standard PME is nested as a special case with restricted parameters of the GPME model. The relaxation of these restrictions in the GPME methodology has the benefit that an investment's specific exposure to risk factors can be incorporated. Beyond market and Treasury Bill returns we add benchmark returns for Fama-French SMB and HML portfolios as additional risk factors to estimate investment-level stochastic discount factors.

In our sample we find the correlation between the standard PME and the GPME to be very high: +0.944. Accordingly, the results of our persistence analysis are robust to controlling for these additional risk factors when measuring performance. Tables replicating the deal-level regressions but using the GPME as dependent variable can be found in the Internet Appendix.

\subsection{Summary}

Altogether, the results in this section show that performance persistence for buyout funds is much lower than previously found, using both fund-level and deal-level data. In part this may be due to the much larger sample of funds we now have available, and the fact that some earlier studies combined VC and buyout funds in their analysis. But there is also strong evidence that performance persistence has been falling over time, as the PE sector has grown, new GPs have entered, and many of the operational, financing and valuation techniques have become assimilated. The competitive state of the market also impacts on performance persistence: when a large amount of capital chases deals, persistence tends to be lower. Therefore, across the whole sample of GPs there is strong evidence that performance persistence has largely disappeared as the market has matured and become more competitive. 


\section{Performance persistence of the best and worst GPs}

\subsection{Does persistence remain in the top and bottom quartiles?}

While we have shown that persistence is weaker in a high competition environment, we do not know whether this applies equally across the performance spectrum. After all, investors are interested in persistent high performance, rather than reliable mediocre GPs. Therefore, in this section we focus on persistence at the top and the bottom of the performance distribution.

To do this we compute binary variables for current and lagged deal PME quartile performance. Analogous to the approached used when analysing fund performance transition matrices (Section 3.1) we assign each investment in our sample into one of four PME performance quartiles by reference to the performance of all other deals in the same investment year.

Relating to the previous regressions (Tables 6 and 7) we run two kinds of Logit regressions. First, we regress current relative performance on lagged relative performance and all controls. Second, we test for the significance of GP fixed effects by likelihood-ratio tests of joint significance. We run these two regressions separately for the top and bottom performance quartiles, and for the low and high competition environments.

The results are presented in Table 8 . We find that top quartile persistence falls significantly when competition is high. In column 1 the coefficient on the lagged top quartile dummy in low competition environments is 0.478 and statistically significant. In economic terms the coefficient indicates that the probability of realizing a top quartile PME return with the current deal is 8.9 percentage points higher if the previous deal by the same GP was top quartile (30.3\% vs. $21.4 \%$ ). In contrast, the much smaller and weakly significant coefficient on the lagged top quartile dummy in high competition PE markets (in column 3) of 0.204 implies limited evidence of top quartile persistence in more competitive market conditions ( $28.2 \%$ vs. $24.4 \%)$. This pattern is confirmed by the Chi-square values from likelihood-ratio tests in columns 2 and 4 . We obtain these values by running unrestricted models for the low and high competition subsamples and estimate equivalent restricted models excluding GP dummies. The Chi-square value for the GP fixed effects in explaining top quartile performance in the low competition subsample is highly significant. The corresponding Chi-square value in the high competition regression is only 
weakly statistically significant. Hence, the evidence suggests that GPs are much less likely to repeat top quartile performance if competition for buyouts is high.

In contrast, the coefficients on lagged bottom quartile deal PME performance in low (column 5) and high (column 7) competition PE market segments are both statistically significant and of comparable economic size. They mean that if the previous investment was among the bottom quartile PME deals the probability of bottom quartile deal performance is 6.3\%-points higher (29.6\% vs. $23.3 \%)$ when competition is low and $7.3 \%$-points (31.1\% vs. $24.0 \%)$ when it is high. In line with this pattern, both likelihood-ratio tests, for the low and high competition subsamples, indicate a significant impact of GP fixed effects in explaining bottom quartile performance at the investment level. Therefore, the evidence suggests that competition has its main impact on the ability of GPs to repeat top performance. The probability of repeating bad deals, relative to peers, is relatively unaffected by competition.

\subsection{Longer-term persistence}

The two different regression approaches presented above - lagged performance and GP fixed effects - analyse persistence in different ways. While the lagged model is short-term in nature, the GP fixed effects approach adopts a long-term perspective and analyzes whether the average return of investments varies across GPs. However, the coefficients on lagged performance also provide some indication on the pace with which returns revert to the sample mean. In the literature on corporate capital structure decisions, AR1 regression set-ups are applied to analyse the extent to which companies adjust their leverage towards a target value every year (see e.g. Flannery and Rangan, 2006; Faulkender et al., 2012). Analogously, we could interpret one minus the coefficient on lagged performance $\left(1-\beta_{\operatorname{PME}(n-1)}\right)$ as the average partial adjustment (between two deals) towards the estimated target PME return in the sample. For example, the coefficient on lagged PME return in low competition states (Table 7, column 2) of 0.118 would translate into an average adjustment speed of $88.2 \%$ (1-0.118) from on investment to the next. This means that if a GP out- or underperforms the estimated return to investments in the overall sample with a given investment, $88.2 \%$ of this gap have already disappeared with the next investment. While already 
indicating a strong mean reversion tendency, this number is still considerably lower than the $96.6 \%$ (1-0.034) for the high competition subsample. ${ }^{21}$

In order to shed more light on this 'half-life' of performance persistence among the best and worst performing GPs, we adapt the approach employed by Carhart (1997) in his analysis of mutual fund managers. Carhart put managers into 10 portfolios according to performance for each period, and tracked the subsequent performance of these portfolios over time. In the case of $\mathrm{PE}$, quarterly or annual fund returns largely reflect changes in estimated asset valuations, rather than out-turn returns, and so using current reported fund performance would be problematic. However, with our deal-level data we are able to analyse whether strong relative performance persists over subsequent deals. We put GPs into performance quartiles according to the relative performance of each deal, and then analyse the performance of portfolios comprising their 10 subsequent deals, and whether the results differ in low and high competition environments.

Specifically, each realized and unique investment is allocated into either the low or the high competition subsample. For both subsamples we compute mean PMEs for these four formation portfolios of deals $\left(\mathrm{n}_{0}\right)$. By definition, the mean returns in these portfolios vary substantially. Panel A in Table 9 shows that the top quartile/low competition deals have a mean gross PME of 5.31. The corresponding average PME for the bottom quartile deals is only 0.15. We compute one-sided T-tests to analyse statistical significance of these differences: one comparing mean PME in the top quartile with the mean of all other quartiles $\left(2^{\text {nd }}\right.$ to $\left.4^{\text {th }}\right)$ and another comparing average bottom quartile performance with all others $\left(1^{\text {st }}\right.$ to $\left.3^{\text {rd }}\right)$.

We then put each next deal $\left(\mathrm{n}_{1}\right)$ by the same GP into the same category as the formation deal $\left(\mathrm{n}_{0}\right)$, irrespective of its own performance, and compute mean PMEs for these four portfolios of subsequent deals. For example, the average PME return to all deals $\mathrm{n}_{1}$ that follow the top quartile investments (within each GP's deal sequence) in the low competition subsample is 2.53 and statistically higher than the mean performance among all other $\mathrm{n}_{1}$ deals. We repeat this procedure for the next nine deals always using the quartile formation set by deal $\mathrm{n}_{0}$. Figure 3 provides an

\footnotetext{
${ }^{21}$ The estimation approach in the literature on debt is different from our regressions displayed in Table 7 in that leverage is regressed on a lagged set of control variables plus fixed effects that are related to the benefits and costs of leverage, and therefore able to predict target leverage, and lagged leverage. Unreported regressions replicating this approach and using the variables shown in Table 7, indicate similar coefficients on lagged PME return, and thus adjustments speeds, as displayed in Table 7.
} 
illustration of the mean PMEs within the four portfolios for the low (Panel A) and the high competition (Panel B) subsamples, respectively.

If investment performance by the same GP is persistent, the differences in returns (mechanically constructed for the formation investment $\mathrm{n}_{0}$ ) should persist across the distribution of subsequent deals. The results confirm that deal-level performance is indeed more persistent and long-lived in periods of low competition: on average, the first to tenth deal after the top quartile formation investment also yield higher PME returns (Table 9, Panel A). All mean values for the top quartile are significantly higher than the average gross PME in the other three groups. This also applies to the bottom quartile in the low competition subsample (with the exception of deals $\mathrm{n}_{2}$ ). Graphically, this pattern results in only few intersections of the lines in Figure 3, Panel A. Here, past performance is informative in that following deals, on average, also yield similar relative returns. This particularly holds for top quartile deal performance that continuously, over the next ten deals, lies above the average deal returns.

In line with the regression results already presented, this long-lived persistence evaporates in high competition PE market segments, particularly at the top of the performance distribution. Panel B in Table 9 indicates that the first three deals following a given deal yield comparable relative performance. T-tests for both, top and bottom, quartiles for deals $\mathrm{n}_{1}$ to $\mathrm{n}_{3}$ are statistically significant indicating some degree of short-lived performance persistence. However, with few exceptions, the succeeding deals from $\mathrm{n}_{4}$ onwards yield no significantly different returns. This is also illustrated in Panel B of Figure 3. While the order of average performance remains stable for three subsequent deals $\left(\mathrm{n}_{1}\right.$ to $\left.\mathrm{n}_{3}\right)$, the lines for the four performance quartiles converge to very similar absolute PME levels after the third following deal. This analysis suggests that mean reversion of returns is much quicker in higher competition periods. ${ }^{22}$

\section{Conclusions}

In this paper we have re-visited the performance persistence of PE buyout fund managers. Whereas previous papers have considered performance across funds, our unique sample of detailed cash flow data for several thousand buyout transactions allows us to strip away the legal

\footnotetext{
22 Furthermore, although we have focussed in this section on the impact of competition on performance persistence, we find similar qualitative results when we split the sample into early and late deals: top (and bottom) quartile performance persistence is much less apparent in recent years.
} 
wrapper of the fund and analyse performance persistence of GPs in new ways. We have gross returns at the deal-level derived from investor due diligence, whereas most previous analyses have used net returns at the fund-level. We are able to avoid issues regarding the valuation of unrealized investments by focussing only on portfolio companies where the fund has fully exited the investment and the return is known. Using deal-level data allows us to address several issues that induce artificial persistence when using fund-level data: common deals in successive funds, market conditions and other common factors that influence returns etc. We analyse persistence by comparing the returns on successive deals and by analysing whether the performance of GPs systematically differs over their entire portfolio of deals. This provides a new lens through which to analyse PE performance persistence and how it has changed as the market has grown and matured.

Our main findings are as follows. First, when we analyse performance persistence in the traditional way, at the fund level, we find evidence of performance persistence, but the effects are much weaker than in previous studies. In particular Kaplan and Schoar (2005) found performance persistence across funds raised until the late-1990s. However, for our much larger and more recent sample of buyout funds we find only weaker evidence of performance persistence. This mirrors the results of recent research on the performance of different types of LPs, in which Sensoy, Wang and Weisbach (2014) find that earlier evidence of out-performance is no longer apparent. Our paper may help to explain their finding: the privileged access to successful GPs became less valuable as the market matured and GP performance persistence disappeared.

Second, taking advantage of our deal-level data, we explore whether the disappearing performance persistence is associated simply with the PE sector becoming mature with the passage of time, or whether competition has a role to play. These explanations are clearly not mutually exclusive, as competition has increased over time, but neither are they equivalent. Competition has developed at a faster pace in some regions, and our global data and classification of deals by industry allows us to proxy the amount of money chasing deals. Across the whole sample of deals we find evidence of performance persistence during low competition periods, but this is barely apparent in periods of high competition Therefore, performance persistence for buyout fund GPs has reduced as the market has matured and become more competitive.

Third, we also analyse whether performance persistence has remained among the top, and bottom, performing funds. We find that the probability of repeating top quartile performance is 
related to the competitive state of the market, with significant top quartile persistence during low competition states, but only marginal evidence of persistence in the high competition periods. Interestingly, we find significant bottom quartile persistence irrespective of the state of the market. The fact that most of the remaining persistence in PE returns is associated with the GPs with the worst relative performance, who manage to raise another fund and disappoint their investors again, raises questions about the due diligence performed by investors. This finding is in line with the argumentation by Phalippou (2010) who argues that underperforming GPs are backed by unsophisticated investors who do not incorporate all available information and therefore repeatedly commit capital to poorly skilled GPs.

Finally, we analyse mean reversion in returns by assigning each deal into a performance quartile and then tracking the performance of the ten subsequent deals by that GP. The top quartile portfolios constructed on this basis exhibit significantly better returns in low competition periods, but reversion to the mean occurs rapidly in periods of high competition. The impact of competition on the bottom quartile of performers is much less apparent.

In summary, this paper finds that performance persistence in PE is influenced by both the competition for deals at any particular time, and also the general maturity of the market. In many respects this conforms with intuition: market practitioners acknowledge that financing and valuation techniques have become commoditized, the number of proprietary deals has fallen, and it seems likely that ways to create operational improvements to portfolio companies have become assimilated across firms. For investors this research has clear, but uncomfortable, implications. The often-heard mantra of sticking with top-performing managers is no longer a recipe for success. If past performance provides little guidance on the choice of GPs, it remains to be seen whether alternative reliable predictors can be found. In common with most other asset classes, PE buyouts have succumbed to mean-reverting tendencies. Understanding the organizational, competitive, incentive or succession challenges faced as GPs mature is beyond the scope of this paper but represents a fertile area for future research. 


\section{References}

Achleitner, A.-K., Braun, R., Engel, N., 2011. Value creation and pricing in buyouts: Empirical evidence from Europe and North America. Review of Financial Economics 20, 146-161.

Barber, B.M., Yasuda, A., 2014. Interim fund performance and fundraising in private equity. Unpublished working paper. University of California, Davis.

Berk, J.B., Green, R.C., 2004. Mutual fund flows and performance in rational markets. Journal of Political Economy, 112, 1269-1295.

Bertrand, M., Schoar, A., 2003. Managing with style: the effect of managers on firm policies. Quarterly Journal of Economics 118, 1169-1208.

Braun, R., Crain, N., Gerl, A., 2015. The levered returns of leveraged buyouts: The impact of competition. Unpublished working paper. Vanderbilt University, Nashville.

Braun, R., Engel, N., Hieber, P., Zagst, R., 2011. The risk appetite of private equity sponsors. Journal of Empirical Finance 18, 815-832.

Brown, G., Gredil, O., Kaplan, S., 2015. Do private equity funds game returns? Unpublished working paper. University of North Carolina.

Brown, G., Harris, R., Jenkinson, T., Kaplan, S., 2012. How big is the private equity universe? Presentation available at http://areas.kenan-flagler.unc.edu/finance/Pages/PERC.aspx .

Brown, G., Harris, R., Jenkinson, T., Kaplan, S., Robinson, D., 2015, What do different commercial data sets tell us about private equity performance? Unpublished working paper, Private Equity Research Consortium, University of North Carolina.

Carhart, M., 1997. On persistence in mutual fund performance. Journal of Finance 52, 57-82.

Chung, J.-W., 2012. Performance persistence in private equity funds. Unpublished working paper. Korea University.

Faulkender, M., Flannery, M., Watson Hankins, K., Smith, J., 2012. Cash flows and leverage adjustments. Journal of Financial Economics 103, 632-646.

Flannery, M., Rangan, K., 2006. Partial adjustment toward target capital stuctures. Journal of Financial Economics 79, 469-506.

Gompers, P., Lerner, J., 2000. Money chasing deals? The impact of fund inflows on private equity valuation. Journal of Financial Economics 55, 281-325.

Harris, R., Jenkinson, T., Stucke, R., 2012. Are too many private equity funds top quartile? Journal of Applied Corporate Finance 24, 77-89. 
Harris, R., Jenkinson, T., Kaplan, S., 2014. Private equity performance: What do we know? Journal of Finance 69, 1851-1882.

Harris, R., Jenkinson, T., Kaplan, S., 2015. How do private equity investments perform compared to public equity? Forthcoming, Journal of Investment Management.

Harris, R., Jenkinson, T., Kaplan, S., Stucke, R., 2013. Has persistence persisted in private equity? Evidence from buyout and venture capital funds. Unpublished working paper. UAI Foundation, University of Virginia.

Hochberg, Y., Ljungqvist, A., Vissing-Jorgensen, A., 2014. Informational hold-up and performance persistence in venture capital. Review of Financial Studies 27, 102-152.

Jagannathan, R., Malakhov, A., Novikov, D., 2010. Do hot hands persist among hedge fund managers? An empirical evaluation, Journal of Finance 65, 217-255.

Jenkinson, T., Sousa, M., Stucke, R., 2013. How fair are the valuations of private equity funds? Unpublished working paper. University of Oxford.

Kaplan, S., Schoar, A., 2005. Private equity performance: Returns, persistence, and capital flows. Journal of Finance 60, 1791-1823.

Kaplan, S., Strömberg, P., 2009. Leveraged buyouts and private equity. Journal of Economic Perspectives, Winter, 121-146.

Kortegweg, A., Nagel, S., 2015, Risk-adjusting the returns to venture capital. Forthcoming, Journal of Finance.

Korteweg, A., Sorensen, M., 2014. Skill and luck in private equity performance. Unpublished working paper. Stanford University.

Lerner, J., Schoar, A., Wongsunwai, W., 2007. Smart institutions, foolish choices: the limited partner performance puzzle. Journal of Finance 62, 731-764.

Ljungqvist, A., Richardson, M., 2003. The cash flow, return, and risk characteristics of private equity. Unpublished working paper. NBER.

Metrick, A., Yasuda, A., 2010. The economics of private equity funds. Review of Financial Studies 23, 2303-2341.

Phalippou, L., 2010. Venture capital funds: Flow-performance relationship and performance persistence. Journal of Banking and Finance 34, 568-577.

Phalippou, L., Gottschalg, O., 2009. The performance of private equity funds. Review of Financial Studies 22, 1747-1776. 
Robinson, D., Sensoy, B., 2013. Cyclicality, Performance Measurement, and Cash Flow Liquidity in Private Equity. Unpublished working paper. Duke University and Ohio State University.

Sensoy, B., Wang, Y., Weisbach, M., 2014. Limited partner performance and the maturing of the private equity industry. Journal of Financial Economics 112, 320-343.

Sorensen, M., Jagannathan, R., 2015. The public market equivalent and private equity performance. Financial Analysts Journals 71, 43-50.

Stoff, I., Braun, R., 2013. The cost of private equity. Unpublished working paper. Technische Universität München.

Stucke, R., 2011. Updating history. Unpublished working paper. University of Oxford. 


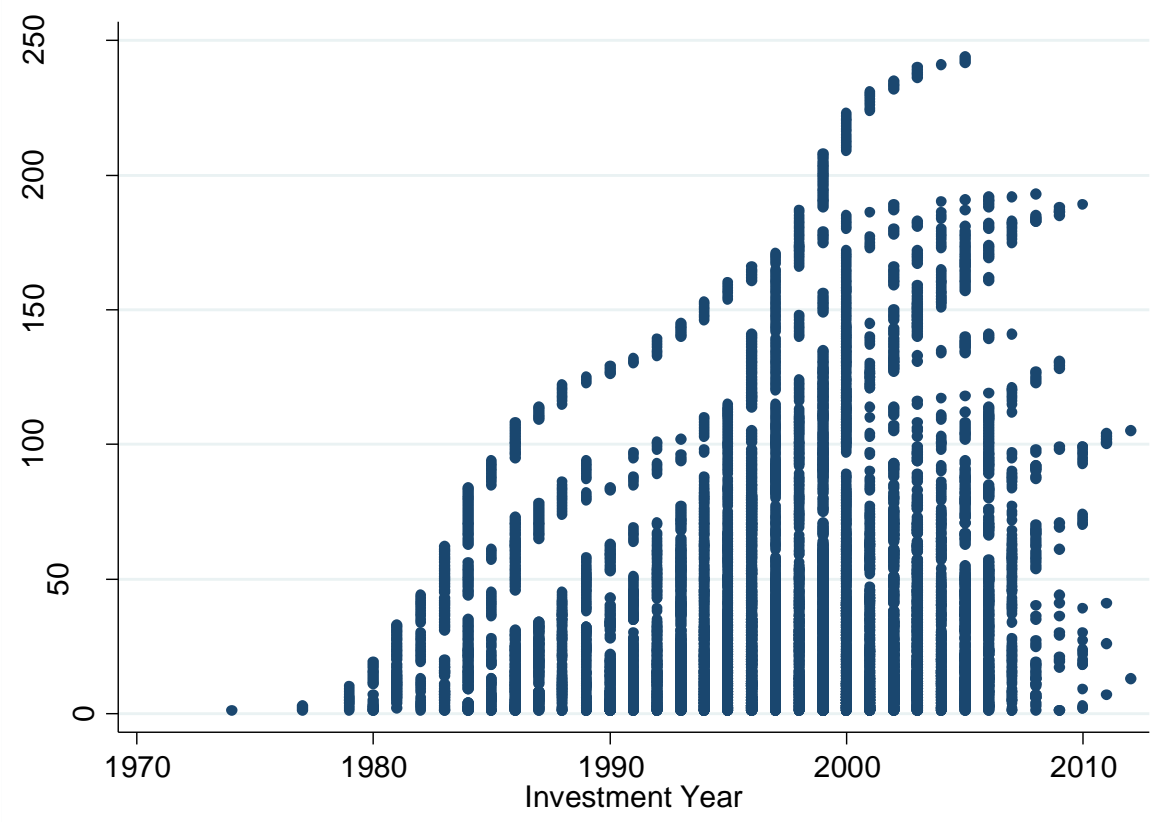

Figure 1. Deal sequences by investment year. This figure shows the deal sequence number of individual deals plotted against the year in which each investment was made. Our sample covers 7,568 realized and unique transactions made between 1974 and 2012. We obtain the deal sequence variable by, first, sequencing all deals done within a certain fund family based on their investment date and, second, counting the number of deals starting with the first deal ever made within the fund family. 


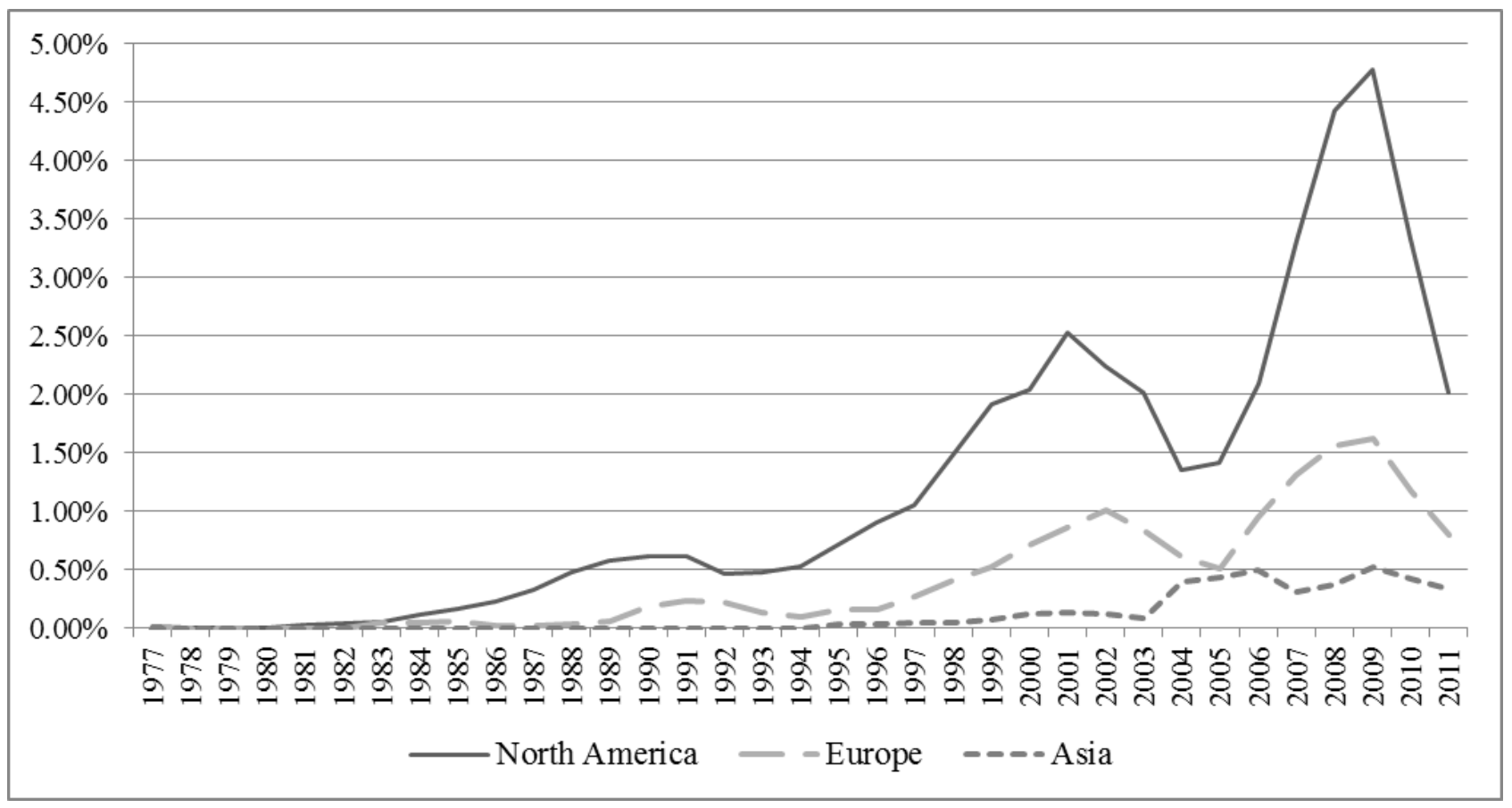

Figure 2. PE competition over time. For each given sample year, this figure illustrates the total buyout funds raised in the previous three years in a given region divided by the same region's GDP in the current year. Numbers on total buyout fundraising in mUSD are taken from the PE universe, consolidating the Burgiss, Preqin and Thomson databases, as presented by Brown et al. (2012). For each vintage year, each buyout fund raised in the PE universe is first assigned to one of three regional private equity markets (North America, Europe or Asia) and, then, split into ten ICB industry groups within each region according to the industry focus reported in the consolidated database. Next, for a given year, say 1999 , the funds assigned to the each region-industry group in the previous three years, in this example 1996, 1997 and 1998, are summed up and serve as a proxy for the demand for buyout. This number is divided by the GPD in the same region and the current year 1999 (in this example). This is supposed to proxy for the number of potential investment opportunities. For the sake of brevity, in this figure we aggregate the industry groups and present this competition proxy for each of the three regional PE markets. 
Panel A: Low competition subsample

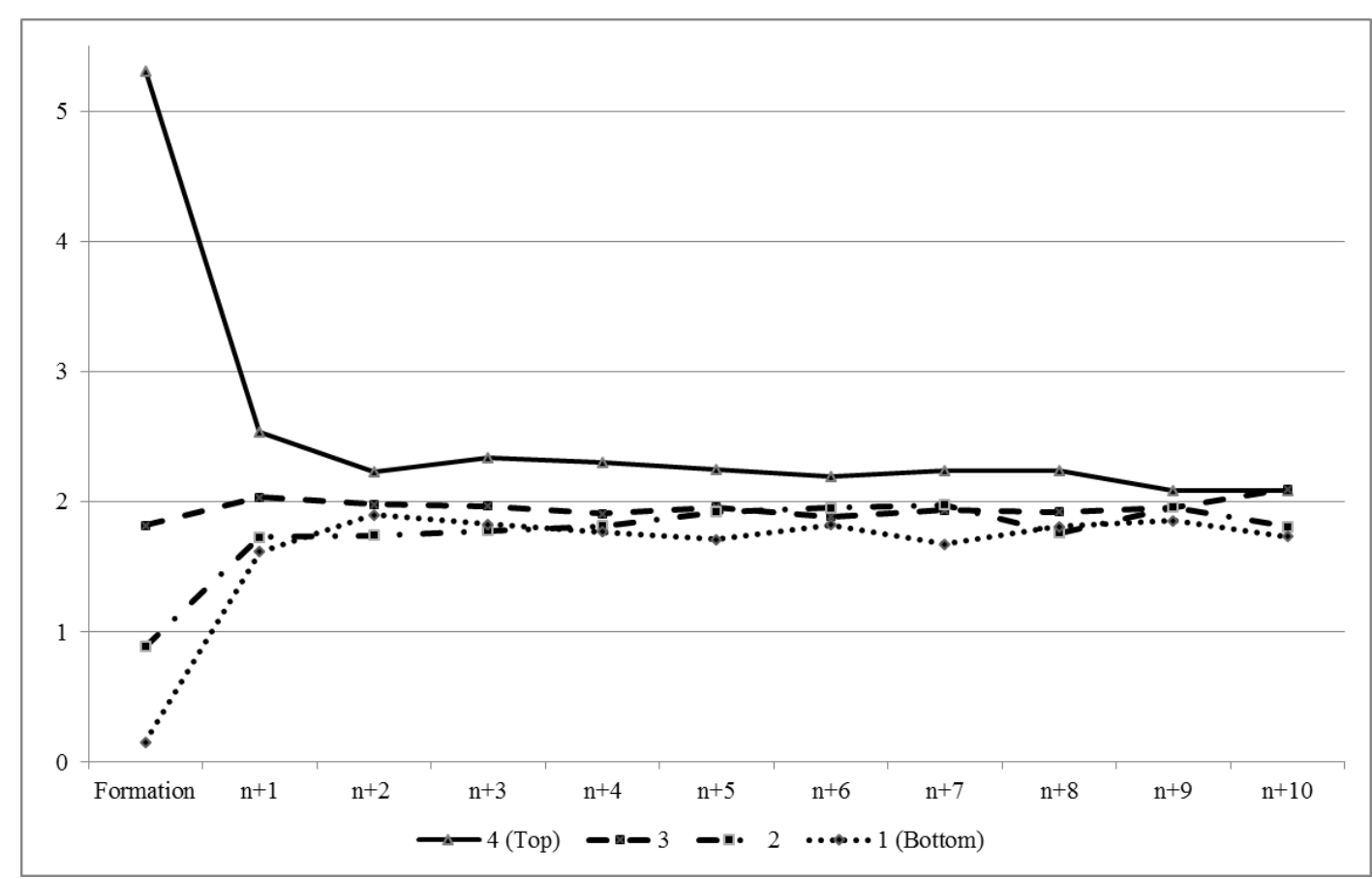

Panel B: High competition subsample

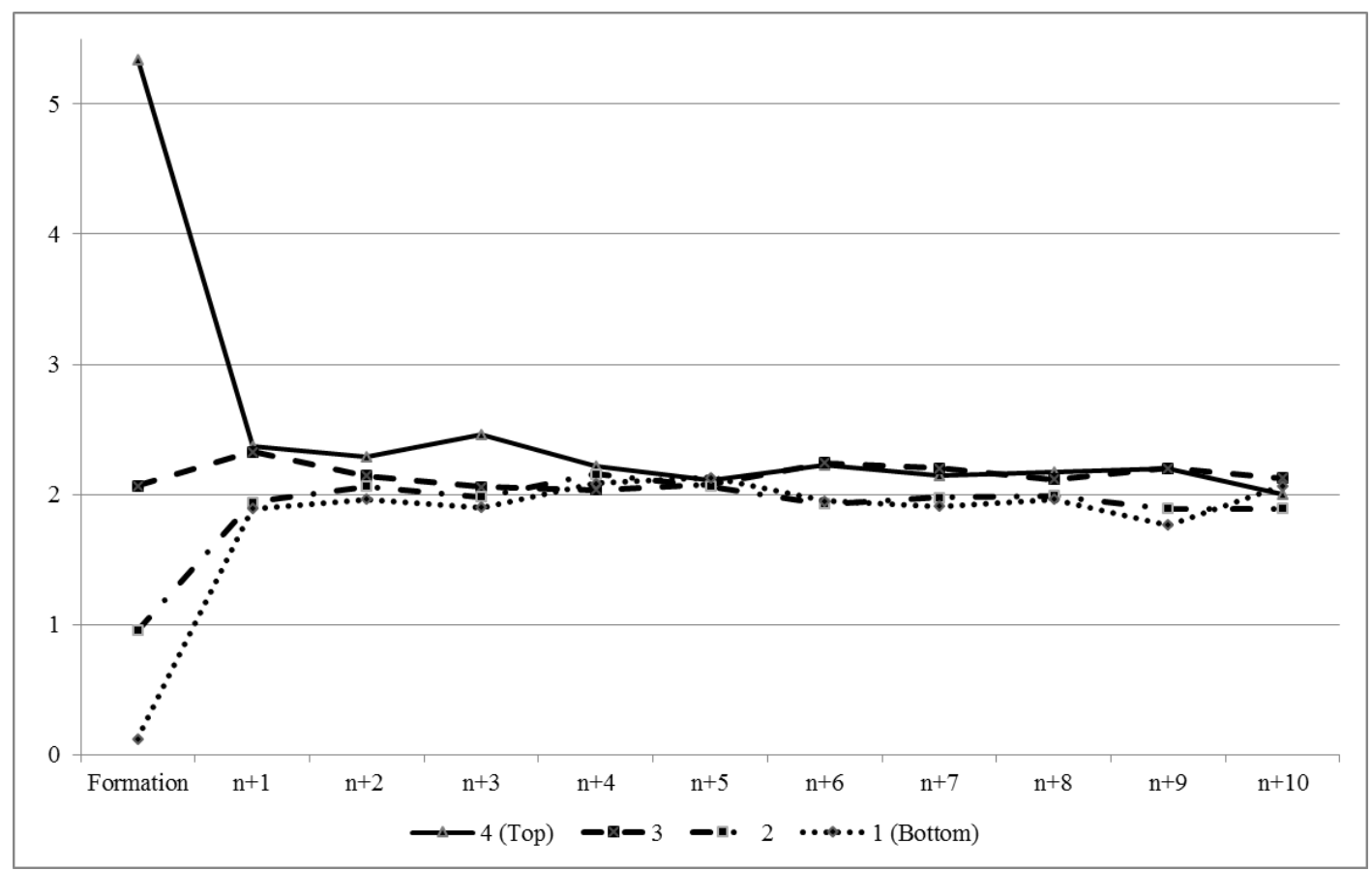

Figure 3. Long term deal PME persistence. These figures illustrate the mean Market Public Equivalent (PME) returns resulting from the procedure in Table 9. Panel A shows investments (and their subsequent deals by the same GP) done in low competition years. Panel B displays mean values for those formation deals done in high competition years. 


\section{Table 1}

\section{The sample of funds and fund families}

This table illustrates the coverage of fund families with our sample of 13,523 realized and unrealized transactions and 865 funds. We assigned each fund to a fund family based on the GP managing the fund. In case a GP runs more than one fund family we formed more than one set of fund sequences for this GP, based on the countries in which the respective fund family operates. This procedure results in a total of 301 fund sequences. In Panel A we indicate the fund generation of the first fund in each fund family that we observe in our sample and the number of subsequent funds that we cover. For example, our sample includes 57 fund families for which we observe the complete sequence of the first, second and third fund. At the right-hand side, instead of length of fund sequence, we show the number of incomplete sequences within a fund family. These numbers indicate that only six fund families in our sample are incomplete in the sense that we do not observe all funds in between the first and last fund of the respective fund family. In Panel B we provide the same information at the fund-level. For example, the 57 fund families for which we observe the complete sequence from the first to the third fund are made up by 171 funds.

\begin{tabular}{|c|c|c|c|c|c|c|c|c|c|c|c|c|c|c|c|c|c|c|}
\hline \multicolumn{19}{|c|}{ Panel A: Number of Fund Families } \\
\hline & & \multirow[b]{2}{*}{1} & \multirow[b]{2}{*}{2} & \multicolumn{6}{|c|}{ Length of fund sequence } & \multicolumn{9}{|c|}{ Incomplete sequences } \\
\hline & & & & 3 & 4 & 5 & 6 & 7 & 8 & 9 & 10 & 2 & 3 & 4 & 5 & 6 & Total & $(\%)$ \\
\hline & 1 & 60 & 66 & 57 & 26 & 25 & 10 & 4 & 1 & 1 & 3 & & & & 2 & $\frac{1}{1}$ & 256 & $(85 \%)$ \\
\hline & 2 & 9 & 2 & 5 & 1 & 1 & & & & & & & & & 1 & & 19 & $(6 \%)$ \\
\hline \multirow{7}{*}{$\begin{array}{l}\text { First fund } \\
\text { in sequence }\end{array}$} & 3 & 2 & 5 & 1 & 2 & 1 & & & & & & 1 & & & & & 12 & $(4 \%)$ \\
\hline & 4 & & 2 & 2 & 2 & 1 & 1 & & & & & & & & & & 8 & $(3 \%)$ \\
\hline & 5 & & & & & & & & & & & & & & & & $\mathbf{0}$ & $(0 \%)$ \\
\hline & 6 & & & 1 & & & 1 & & & & & & & & & & 2 & $(1 \%)$ \\
\hline & 7 & 1 & & 1 & & & & & & & & & & & & & 2 & $(1 \%)$ \\
\hline & 8 & & & 1 & & & & & & & & & & & 1 & & 2 & $(\mathbf{1 \%})$ \\
\hline & & 72 & 75 & 68 & 31 & 28 & 12 & 4 & 1 & 1 & 3 & 1 & & & 4 & 1 & 301 & $(100 \%)$ \\
\hline
\end{tabular}

Panel B: Number of Funds

\begin{tabular}{|c|c|c|c|c|c|c|c|c|c|c|c|c|c|c|c|c|c|c|}
\hline & & \multirow[b]{2}{*}{1} & \multicolumn{8}{|c|}{ Length of fund sequence } & \multicolumn{6}{|c|}{ Incomplete sequences } & \multirow[b]{2}{*}{ Total } & \multirow[b]{2}{*}{$(\%)$} \\
\hline \multirow{10}{*}{$\begin{array}{l}\text { First fund } \\
\text { in sequence }\end{array}$} & & & 2 & 3 & 4 & 5 & 6 & 7 & 8 & 9 & 10 & 2 & 3 & 4 & 5 & 6 & & \\
\hline & 1 & 60 & 132 & 171 & 104 & 125 & 60 & 28 & 8 & 9 & 30 & & & & 10 & 6 & 743 & $(86 \%)$ \\
\hline & 2 & 9 & 4 & 15 & 4 & 5 & & & & & & & & & 5 & & 42 & $(5 \%)$ \\
\hline & 3 & 2 & 10 & 3 & 8 & 5 & & & & & & 2 & & & & & 30 & $(3 \%)$ \\
\hline & 4 & & 4 & 6 & 8 & 5 & 6 & & & & & & & & & & 29 & $(3 \%)$ \\
\hline & 5 & & & & & & & & & & & & & & & & 0 & $(0 \%)$ \\
\hline & 7 & & & 3 & & & 6 & & & & & & & & & & 9 & $(1 \%)$ \\
\hline & 6 & 1 & & 3 & & & & & & & & & & & & & 4 & $(0 \%)$ \\
\hline & 8 & & & 3 & & & & & & & & & & & 5 & & 8 & $(1 \%)$ \\
\hline & & 72 & 150 & 204 & 124 & 140 & 72 & 28 & 8 & 9 & 30 & 2 & 0 & 0 & 20 & 6 & 865 & $(100 \%)$ \\
\hline
\end{tabular}




\section{Table 2}

\section{Fund descriptives}

Table 2 reports fund-level characteristics of our sample of all 865 buyout funds by fund vintage years. The table shows the mean fund size in million of USD and mean fund generation number. Furthermore, it describes the mean realization status of the 13,523 deals with-in the 865 funds as well as mean and median gross fund returns (winsorized at the 99th percentile) for fund Market Public Equivalents (PME) and multiple of invested capital (MOIC). We use the three regional MSCI Performance Indices (Asia, Europe, North America) in local currency as benchmarks for our PME calculations and use the regional index where the GP is located. Next, the table shows the average of total deals in a fund and indicates how many of these are realized, partially realized and unrealized in our sample. Further, the number of common deals per fund are exhibited. Common deals are those investments that a GP has done through more than one fund. Lastly, the table shows the number of funds with a previous fund within the same fund family.

\begin{tabular}{|c|c|c|c|c|c|c|c|c|c|c|c|c|c|}
\hline \multirow[b]{3}{*}{ Fund Vintage } & \multirow{3}{*}{ \# Funds } & \multirow{3}{*}{$\begin{array}{c}\text { Mean } \\
\text { Fund Size } \\
\text { [m USD] }\end{array}$} & \multirow{3}{*}{$\begin{array}{c}\text { Mean } \\
\text { Fund } \\
\text { Genera- } \\
\text { tion } \\
\text { Number }\end{array}$} & \multicolumn{4}{|c|}{ Fund Gross Returns } & \multicolumn{4}{|c|}{ Mean \# of Deals per Fund } & \multirow{3}{*}{$\begin{array}{c}\text { Mean \# of } \\
\text { Common } \\
\text { Deals per } \\
\text { Fund }\end{array}$} & \multirow{3}{*}{$\begin{array}{l}\text { Funds with a } \\
\text { Previous } \\
\text { Fund }\end{array}$} \\
\hline & & & & \multicolumn{2}{|c|}{ PME } & \multicolumn{2}{|c|}{ MOIC } & \multirow[t]{2}{*}{ Total } & \multirow[t]{2}{*}{ Realized } & \multirow{2}{*}{$\begin{array}{l}\text { Partially } \\
\text { Realized }\end{array}$} & \multirow{2}{*}{$\begin{array}{c}\text { Unrea- } \\
\text { lized }\end{array}$} & & \\
\hline & & & & Mean & Median & Mean & Median & & & & & & \\
\hline 1974 & 1 & 125 & 1.0 & 6.7 & 6.7 & 3.1 & 3.1 & 7.0 & 7.0 & 0.0 & 0.0 & 0.0 & 0 \\
\hline 1976 & 1 & 31 & 1.0 & 4.8 & 4.8 & 9.7 & 9.7 & 7.0 & 7.0 & 0.0 & 0.0 & 0.0 & 0 \\
\hline 1979 & 1 & 42 & 1.0 & 1.5 & 1.5 & 1.8 & 1.8 & 30.0 & 30.0 & 0.0 & 0.0 & 3.0 & 0 \\
\hline 1980 & 5 & 102 & 1.4 & 2.3 & 1.6 & 3.2 & 3.0 & 28.4 & 28.0 & 0.2 & 0.2 & 1.8 & 2 \\
\hline 1982 & 1 & 68 & 1.0 & 3.3 & 3.3 & 4.5 & 4.5 & 18.0 & 18.0 & 0.0 & 0.0 & 0.0 & 0 \\
\hline 1983 & 4 & 161 & 2.3 & 1.2 & 1.2 & 2.3 & 2.4 & 37.0 & 36.3 & 0.8 & 0.0 & 2.5 & 3 \\
\hline 1984 & 8 & 186 & 1.6 & 2.8 & 2.5 & 3.6 & 3.8 & 21.8 & 21.6 & 0.1 & 0.0 & 0.1 & 3 \\
\hline 1985 & 6 & 250 & 1.8 & 1.5 & 1.5 & 2.2 & 2.1 & 19.7 & 19.7 & 0.0 & 0.0 & 2.2 & 2 \\
\hline 1986 & 9 & 186 & 1.9 & 2.6 & 1.9 & 3.8 & 3.2 & 21.4 & 20.4 & 1.0 & 0.0 & 1.0 & 4 \\
\hline 1987 & 10 & 882 & 2.1 & 2.6 & 1.7 & 3.2 & 2.6 & 15.2 & 14.5 & 0.7 & 0.0 & 0.2 & 5 \\
\hline 1988 & 12 & 129 & 1.8 & 1.8 & 1.6 & 3.2 & 2.9 & 13.4 & 13.2 & 0.3 & 0.0 & 0.3 & 6 \\
\hline 1989 & 16 & 262 & 2.0 & 2.2 & 1.9 & 3.3 & 3.4 & 18.8 & 18.7 & 0.1 & 0.0 & 1.6 & 6 \\
\hline 1990 & 22 & 341 & 1.3 & 1.9 & 1.9 & 2.8 & 2.6 & 17.4 & 16.2 & 0.9 & 0.3 & 0.2 & 3 \\
\hline 1991 & 15 & 325 & 1.5 & 2.3 & 1.9 & 3.4 & 2.8 & 35.1 & 31.3 & 3.7 & 0.2 & 0.3 & 5 \\
\hline 1992 & 13 & 294 & 1.7 & 2.4 & 1.6 & 3.0 & 2.6 & 11.4 & 10.2 & 0.5 & 0.6 & 0.1 & 2 \\
\hline 1993 & 19 & 369 & 2.5 & 2.1 & 1.7 & 3.3 & 2.7 & 16.9 & 14.9 & 0.9 & 1.1 & 1.2 & 11 \\
\hline 1994 & 30 & 291 & 2.0 & 2.1 & 2.0 & 2.7 & 2.4 & 19.9 & 18.0 & 1.3 & 0.5 & 2.1 & 16 \\
\hline 1995 & 31 & 545 & 2.1 & 2.2 & 1.8 & 2.5 & 2.2 & 16.9 & 13.8 & 2.7 & 0.5 & 0.6 & 19 \\
\hline 1996 & 36 & 396 & 2.5 & 2.4 & 1.9 & 2.6 & 2.2 & 14.1 & 11.5 & 1.7 & 0.9 & 0.6 & 19 \\
\hline 1997 & 43 & 684 & 2.7 & 2.1 & 1.9 & 2.1 & 2.0 & 16.5 & 13.4 & 1.7 & 1.4 & 0.6 & 29 \\
\hline 1998 & 60 & 706 & 2.9 & 2.2 & 2.1 & 2.0 & 2.0 & 14.6 & 10.3 & 2.4 & 1.9 & 1.1 & 42 \\
\hline 1999 & 55 & 672 & 2.2 & 2.3 & 2.2 & 2.4 & 2.3 & 15.1 & 10.1 & 3.6 & 1.4 & 0.7 & 28 \\
\hline 2000 & 72 & 786 & 2.9 & 2.2 & 2.0 & 2.4 & 2.2 & 15.5 & 9.8 & 3.6 & 2.1 & 1.3 & 46 \\
\hline 2001 & 49 & 1,069 & 2.8 & 2.2 & 2.2 & 2.5 & 2.3 & 17.6 & 10.4 & 3.9 & 3.3 & 1.7 & 27 \\
\hline 2002 & 26 & 1,021 & 3.2 & 2.1 & 2.0 & 2.4 & 2.4 & 14.7 & 8.5 & 3.7 & 2.5 & 0.8 & 18 \\
\hline 2003 & 46 & 929 & 2.8 & 2.1 & 2.0 & 2.3 & 2.2 & 15.1 & 6.2 & 5.4 & 3.5 & 0.6 & 31 \\
\hline 2004 & 48 & 952 & 3.1 & 2.1 & 1.8 & 2.0 & 1.9 & 10.9 & 2.6 & 4.3 & 4.0 & 0.7 & 37 \\
\hline 2005 & 66 & 1,800 & 3.5 & 1.8 & 1.6 & 1.7 & 1.5 & 14.2 & 4.1 & 4.7 & 5.4 & 0.9 & 60 \\
\hline 2006 & 68 & 2,534 & 4.3 & 1.4 & 1.3 & 1.4 & 1.3 & 12.8 & 1.6 & 5.4 & 5.8 & 1.1 & 61 \\
\hline 2007 & 53 & 2,181 & 3.6 & 1.6 & 1.4 & 1.6 & 1.5 & 16.1 & 2.2 & 7.7 & 6.2 & 1.3 & 46 \\
\hline 2008 & 29 & 2,054 & 4.0 & 1.4 & 1.2 & 1.5 & 1.4 & 11.0 & 1.0 & 4.6 & 5.4 & 1.2 & 23 \\
\hline 2009 & 7 & 1,618 & 3.1 & 1.3 & 1.2 & 1.5 & 1.3 & 10.9 & 2.4 & 4.9 & 3.6 & 0.7 & 7 \\
\hline 2010 & 3 & 1,955 & 6.3 & 1.2 & 1.2 & 1.1 & 1.1 & 8.3 & 0.0 & 2.0 & 6.3 & 4.7 & 3 \\
\hline Total & 865 & 1,045 & 2.8 & 2.0 & 1.8 & 2.3 & 2.0 & 15.6 & 9.5 & 3.4 & 2.7 & 1.0 & 564 \\
\hline
\end{tabular}




\section{Table 3}

\section{Realized deal descriptives}

This table reports median values for the 12,541 unique investments in our sample. We display performance (winsorized at the 99th percentile) in terms of Public Market Equivalents (PME) and multiple of invested capital (MOIC). We use the three regional MSCI Performance Indices (Asia, Europe, North America) in local currency as benchmarks for our PME calculations and use the regional index where the GP is located. Further, we show investment year, equity investment size in million of USD and the holding period in years. Panel A displays median values by realization status. All other Panels (B) to (E) show descriptives for 7,568 fully realized unique deals only. In Panel B, these investments are assigned to five time categories (based on Kaplan and Stromberg, 2008). In Panel C, we differentiate between the three major regional PE markets and all other regions. For the sake of brevity, in terms of industries we only display the median values across the five most frequent ICB industries in Panel D. Finally, we sort all deals by their sequence number, i.e. sort each unique realized deal by the same GP by investment date and then assign a count variable to each deal. Descriptives for seven deal sequence categories are shown in Panel E.

\begin{tabular}{|c|c|c|c|c|c|c|}
\hline \multirow[b]{3}{*}{ Panel A: Realization status } & \multirow[b]{2}{*}{ Obs. } & \multicolumn{5}{|c|}{ Median } \\
\hline & & PME & MOIC & $\begin{array}{c}\text { Investment } \\
\text { Year }\end{array}$ & $\begin{array}{c}\text { Equity } \\
\text { Investment }\end{array}$ & $\begin{array}{l}\text { Holding } \\
\text { Period }\end{array}$ \\
\hline & \\
\hline All deals & 12,541 & 1.3 & 1.5 & 2001 & 16.3 & 3.8 \\
\hline Unrealized & 2,207 & 1.0 & 1.0 & 2006 & 31.4 & 1.8 \\
\hline Partially Realized & 2,766 & 1.4 & 1.6 & 2005 & 31.6 & 3.8 \\
\hline Fully Realized & 7,568 & 1.4 & 1.9 & 1998 & 9.8 & 4.3 \\
\hline \multicolumn{7}{|c|}{ Panel B: Time categories (only fully realized deals) } \\
\hline 1974-1989 & 806 & 0.9 & 1.7 & 1986 & 1.7 & 5.6 \\
\hline 1990-1994 & 1,292 & 1.3 & 2.2 & 1993 & 4.5 & 4.8 \\
\hline 1995-1999 & 2,410 & 1.4 & 1.9 & 1997 & 9.8 & 4.8 \\
\hline $2000-2004$ & 2,267 & 1.7 & 2.0 & 2002 & 16.2 & 3.9 \\
\hline $2005-2013$ & 793 & 1.3 & 1.5 & 2006 & 27.7 & 2.5 \\
\hline \multicolumn{7}{|c|}{ Panel C: Region categories (only fully realized deals) } \\
\hline Asia & 193 & 1.4 & 1.6 & 2002 & 16.0 & 3.6 \\
\hline Europe & 3,718 & 1.5 & 2.0 & 1999 & 8.6 & 4.2 \\
\hline North America & 3,121 & 1.3 & 1.9 & 1997 & 11.3 & 4.5 \\
\hline Other & 536 & 1.3 & 1.6 & 1997 & 7.8 & 4.0 \\
\hline \multicolumn{7}{|c|}{ Panel D: Industry categories (only major industries, only fully realized deals) } \\
\hline Industrials & 1,885 & 1.5 & 2.1 & 1998 & 9.6 & 4.5 \\
\hline Consumer goods & 1,191 & 1.4 & 2.0 & 1998 & 11.3 & 4.4 \\
\hline Consumer services & 1,038 & 1.4 & 2.0 & 1999 & 14.2 & 4.2 \\
\hline Technology & 945 & 1.2 & 1.6 & 1999 & 6.8 & 4.5 \\
\hline Other & 2,509 & 1.3 & 1.8 & 1998 & 9.1 & 4.0 \\
\hline \multicolumn{7}{|c|}{ Panel E: Sequence categories (only fully realized deals) } \\
\hline$<=20$ & 3,229 & 1.5 & 2.1 & 1997 & 8.7 & 4.3 \\
\hline $21-40$ & 1,600 & 1.3 & 1.8 & 1998 & 9.2 & 4.4 \\
\hline $41-60$ & 940 & 1.4 & 1.9 & 1999 & 10.0 & 4.3 \\
\hline $61-80$ & 589 & 1.3 & 2.0 & 1999 & 8.9 & 4.2 \\
\hline $81-100$ & 385 & 1.1 & 1.5 & 1999 & 9.5 & 4.0 \\
\hline $101-150$ & 526 & 1.2 & 1.6 & 2000 & 13.1 & 4.3 \\
\hline$>150$ & 299 & 1.7 & 2.0 & 2001 & 28.6 & 4.0 \\
\hline
\end{tabular}




\section{Table 4}

\section{Fund performance transition matrix}

This table presents the conditional probabilities that the current fund of a GP $\left(\mathrm{n}_{0}\right)$ either stays in the same performance tercile as the next one $\left(n_{+1}\right)$ within the fund family or belongs to another tercile based on the Public Market Equivalent (PME) gross of fees and carried interest. Fund performance terciles are built across all funds of a given fund vintage year, e.g. we rank all funds of the vintage year 1999 according to their PME performance and build three terciles, containing top funds, mid-performing funds, and bottom funds, respectively. We only include mature funds that are at least $50 \%$ realised in this analysis. We obtain a sample of 534 mature funds with a mature follow-on fund.

\begin{tabular}{|c|c|c|c|c|}
\hline & & \multicolumn{3}{|c|}{ Tercile Fund $_{\mathrm{t} 1}(\%)$} \\
\hline & & Top & Mid & Bottom \\
\hline \multirow{3}{*}{$\begin{array}{l}\text { Tercile } \\
\text { Fund }_{\mathrm{t} 0}\end{array}$} & Top & 39 & 30 & 31 \\
\hline & Mid & 29 & 37 & 34 \\
\hline & Bottom & 26 & 34 & 40 \\
\hline \multicolumn{2}{|c|}{ Pearson chi2 $(4)=9.0304$} & $\operatorname{Pr}=0.060$ & & \\
\hline
\end{tabular}




\section{Table 5}

Performance persistence: full sample

In models (1) to (6), this table presents the results from deal-level OLS regressions of gross Public Market Equivalent (PME) returns on the PME of the previous deal $\left(\mathrm{n}_{-1}\right)$ by the same GP, both winsorized at the 99th percentile. We use the three regional MSCI Performance Indices (Asia, Europe, North America) in local currency as benchmarks for our PME calculations and use the regional index where the GP is located. We only include fully realized unique deals for this analysis. While model (1) includes no control variables, in model (2) we add the log of deal sequence, the log of the equity investment size in million of USD, the log of the holding period and the log of fund age at investment date. In model (3) we also include industry and region fixed effects, and model (4) adds investment year fixed effects. To control for the effect of any first-time fund sampling bias, in model (5) we exclude all deals with a deal sequence below 11 (equal to the mean number of realized deals per first-timer fund in our sample). Finally, model (6) excludes lagged performance but includes GP fixed effects; the joint significance of the GP fixed effects is tested using an F-test. Standard errors are adjusted for serial correlation and heteroskedasticity and exhibited in parentheses. $* * *$ and $* * *$ denote statistical significance at the $10 \%, 5 \%$ and $1 \%$ levels respectively.

\section{Deal $_{n=0}$ Gross PME}

VARIABLES

Deal $_{n-1}$ PME

LN Deal Sequence

LN Equity Investment

LN Holding Period

LN Fund Age

Industry FE

Region FE

Investment Year FE

GP FE

Constant

Observations

Adj. R-squared
OLS: Full Sample

(1)

$0.102 * * *$

(0.015)
(2)

(3)

(0.015)
(4)

$0.094 * * * \quad 0.090 * * * \quad 0.078 * * *$

(0.015)

$-0.234 * * *$
$(0.042)$
$-0.059 * * *$

$-0.059^{* * * *}$

(0.022)

$0.325^{* * * *}$

(0.036)

$0.313 * * *$

(0.068)

$-0.242 * * *$

(0.044)

$-0.067 * * *$

(0.023)

$0.317 * * *$

(0.037)

$0.313^{* * *}$

(0.068)

\section{No}

\section{No}

No

No

$1.841 * * *$

(0.039)

7,289

0.010

\section{No}

No

No

$1.770 * * *$

(0.114)

7,289

0.024

\section{Yes}

Yes

No

No

$1.940 * * *$

(0.147)

7,289

0.033
(0.015)

$-0.240^{* * *}$

(0.045)

$-0.098^{* * * *}$

(0.024)

$0.361 * * *$

(0.039)

$0.232 * * *$

(0.069)

Yes

Yes

Yes

No

$2.449 * * *$

(0.353)
0.049
OLS: deal sequence $>10$

(5)

$0.063 * * *$

(0.017)

$-0.141 * *$

(0.055)

$-0.076^{* * * *}$

(0.026)

$0.370 * * *$

(0.042)

$0.178^{* * *}$

(0.073)

Yes

Yes

Yes

No

$2.368 * * *$

(0.459)

5,586

0.047
GP Fixed Effects

(6)

$-0.255^{* *}$

(0.102)

$-0.211 * * *$

(0.022)

$0.412 * * *$

(0.045)

0.184

(0.159)

Yes

Yes

Yes

Yes

$3.455 * * *$

(1.026)

7,568

0.120

\section{F-test on GP FE}

Standard errors in parentheses 


\section{Table 6}

\section{Performance persistence: early vs. late period}

This table presents the results from deal-level OLS regressions of gross Public Market Equivalent (PME) returns on the PME of the previous deal $\left(\mathrm{n}_{-1}\right)$ by the same GP, both winsorized at the 99th percentile. We use the three regional MSCI Performance Indices (Asia, Europe, North America) in local currency as benchmarks for our PME calculations and use the regional index where the GP is located. We only include fully realized unique deals for this analysis. We split the sample of deals into an early PE market subsample of all investments done before 2001, to mimic the sample period of KS who include highly realized funds with fund vintages up to 1995 for their persistence analysis. Models (1), (2) and (3) report results for this early PE market subsample, models (4), (5) and (6) for all investment years after 2000. Models (1) and (4) include no control variables. In models (2) and (5) we add the log of deal sequence, the log of the equity investment size in million of USD, the log of the holding period in years, the log of fund age at investment date in years as well as investment year, industry and region fixed effects. Finally, models (3) and (6) show results from fixed effects regressions in which we add GP fixed effects but exclude lagged PME. The row at the bottom reports F-statistics from testing joint significance of the GP fixed effects in regressions (3) and (6). Standard errors are adjusted for serial correlation and heteroskedasticity and exhibited in parentheses. *,** and *** denote statistical significance at the $10 \%, 5 \%$ and $1 \%$ levels respectively.

\begin{tabular}{|c|c|c|c|c|c|c|}
\hline \multirow{3}{*}{ VARIABLES } & \multicolumn{6}{|c|}{ Deal $_{\mathrm{n}=0}$ Gross PME } \\
\hline & \multicolumn{3}{|c|}{ Early Investment Years (1979-2000) } & \multicolumn{3}{|c|}{ Late Investment Years (2001-2012) } \\
\hline & (1) & (2) & (3) & (4) & $(5)$ & (6) \\
\hline Deal $_{n-1}$ PME & $\begin{array}{c}0.119 * * * \\
(0.018)\end{array}$ & $\begin{array}{c}0.095^{* * * *} \\
(0.018)\end{array}$ & & $\begin{array}{l}0.047 * * \\
(0.023)\end{array}$ & $\begin{array}{c}0.022 \\
(0.022)\end{array}$ & \\
\hline LN Deal Sequence & & $\begin{array}{c}-0.330 * * * \\
(0.055)\end{array}$ & $\begin{array}{c}-0.287 * * \\
(0.129)\end{array}$ & & $\begin{array}{l}-0.050 \\
(0.073)\end{array}$ & $\begin{array}{l}-0.164 \\
(0.259)\end{array}$ \\
\hline LN Equity Investment & & $\begin{array}{c}-0.113 * * * \\
(0.031)\end{array}$ & $\begin{array}{c}-0.268 * * * \\
(0.030)\end{array}$ & & $\begin{array}{c}-0.085^{* *} \\
(0.042)\end{array}$ & $\begin{array}{c}-0.159 * * * \\
(0.036)\end{array}$ \\
\hline LN Holding Period & & $\begin{array}{c}0.293 * * * \\
(0.046)\end{array}$ & $\begin{array}{c}0.363 * * * \\
(0.053)\end{array}$ & & $\begin{array}{c}0.580 * * * \\
(0.071)\end{array}$ & $\begin{array}{c}0.644 * * * \\
(0.094)\end{array}$ \\
\hline LN Fund Age & & $\begin{array}{c}0.312 * * * \\
(0.084)\end{array}$ & $\begin{array}{l}0.507 * * \\
(0.225)\end{array}$ & & $\begin{array}{c}0.034 \\
(0.122)\end{array}$ & $\begin{array}{l}-0.354 \\
(0.350)\end{array}$ \\
\hline Investment Year FE & No & Yes & Yes & No & Yes & Yes \\
\hline Industry FE & No & Yes & Yes & No & Yes & Yes \\
\hline Region FE & No & Yes & Yes & No & Yes & Yes \\
\hline GP FE & No & No & Yes & No & No & Yes \\
\hline Constant & $\begin{array}{c}1.735 * * * \\
(0.046)\end{array}$ & $\begin{array}{l}0.795^{* *} \\
(0.343)\end{array}$ & $\begin{array}{c}2.539 * * * \\
(0.709)\end{array}$ & $\begin{array}{c}2.119 * * * \\
(0.073)\end{array}$ & $\begin{array}{c}2.249 * * * \\
(0.827)\end{array}$ & $\begin{array}{c}4.828 * * * \\
(1.223)\end{array}$ \\
\hline Observations & 5,037 & 5,037 & 5,244 & 2,252 & 2,252 & 2,324 \\
\hline Adj. R-squared & 0.015 & 0.052 & 0.139 & 0.002 & 0.066 & 0.171 \\
\hline F-test on $G P F E$ & - & - & $\begin{array}{c}F(206,4993)= \\
2.686^{* * *}\end{array}$ & - & - & $\begin{array}{c}F(239,2051)= \\
1.107\end{array}$ \\
\hline
\end{tabular}




\section{Table 7}

\section{Performance persistence: low vs. high competition periods}

This table presents the results from deal-level OLS regressions of gross Public Market Equivalent (PME) returns on the PME of the previous deal $\left(\mathrm{n}_{-1}\right)$ by the same GP, both winsorized at the 99th percentile. We use the three regional MSCI Performance Indices (Asia, Europe, North America) in local currency as benchmarks for our PME calculations and use the regional index where the GP is located. We only include fully realized unique deals for this analysis. We split the sample of deals into low and high competition subsamples at the median competition level in our sample. We use the sum of buyout funds raised in the three years prior to a given transaction, in the same region and industry divided by the GDP in the same (investment) year and region as proxy for competition. Models (1), (2) and (3) report results for the low competition subsample, models (4), (5) and (6) for all investments done in an above median competition environment. Models (1) and (4) include no control variables. In models (2) and (5) we add the log of deal sequence, the log of the equity investment size in million of USD, the log of the holding period in years, the log of fund age at investment date in years as well as investment year, industry and region fixed effects. Finally, models (3) and (6) show results from fixed effects regressions in which we add GP fixed effects but exclude lagged PME. The row at the bottom reports F-statistics from testing joint significance of the GP fixed effects in regressions (3) and (6). Standard errors are adjusted for serial correlation and heteroskedasticity and exhibited in parentheses. $*, * *$ and $* * *$ denote statistical significance at the $10 \%, 5 \%$ and $1 \%$ levels respectively.

\begin{tabular}{|c|c|c|c|c|c|c|}
\hline \multirow{3}{*}{ VARIABLES } & \multicolumn{6}{|c|}{ Deal $_{n=0}$ Gross PME $^{-}$} \\
\hline & \multicolumn{3}{|c|}{ Low Competition } & \multicolumn{3}{|c|}{ High Competition } \\
\hline & (1) & (2) & (3) & (4) & (5) & (6) \\
\hline Deal $_{n-1}$ PME & $\begin{array}{c}0.147 * * * \\
(0.024)\end{array}$ & $\begin{array}{c}0.118 * * * \\
(0.024)\end{array}$ & & $\begin{array}{c}0.057 * * * \\
(0.018)\end{array}$ & $\begin{array}{l}0.034 * \\
(0.017)\end{array}$ & \\
\hline LN Deal Sequence & & $\begin{array}{c}-0.298 * * * \\
(0.066)\end{array}$ & $\begin{array}{l}-0.198 \\
(0.140)\end{array}$ & & $\begin{array}{c}-0.199 * * * \\
(0.061)\end{array}$ & $\begin{array}{l}-0.356^{*} \\
(0.190)\end{array}$ \\
\hline LN Equity Investment & & $\begin{array}{c}-0.103 * * * * \\
(0.033)\end{array}$ & $\begin{array}{c}-0.283 * * * \\
(0.034)\end{array}$ & & $\begin{array}{c}-0.096 * * * \\
(0.037)\end{array}$ & $\begin{array}{c}-0.187 * * * \\
(0.032)\end{array}$ \\
\hline LN Holding Period & & $\begin{array}{c}0.219 * * * \\
(0.058)\end{array}$ & $\begin{array}{c}0.298 * * * \\
(0.063)\end{array}$ & & $\begin{array}{c}0.480 * * * \\
(0.052)\end{array}$ & $\begin{array}{c}0.510 * * * \\
(0.067)\end{array}$ \\
\hline LN Fund Age & & $\begin{array}{c}0.416^{* * * *} \\
(0.107)\end{array}$ & $\begin{array}{l}-0.010 \\
(0.253)\end{array}$ & & $\begin{array}{c}0.092 \\
(0.095)\end{array}$ & $\begin{array}{c}0.199 \\
(0.251)\end{array}$ \\
\hline Investment Year FE & No & Yes & Yes & No & Yes & Yes \\
\hline Industry FE & No & Yes & Yes & No & Yes & Yes \\
\hline Region FE & No & Yes & Yes & No & Yes & Yes \\
\hline GP FE & No & No & Yes & No & No & Yes \\
\hline Constant & $\begin{array}{c}1.686 * * * \\
(0.055)\end{array}$ & $\begin{array}{l}1.560 \\
(1.197)\end{array}$ & $\begin{array}{c}1.704 \\
(1.710)\end{array}$ & $\begin{array}{c}2.001 * * * \\
(0.056)\end{array}$ & $\begin{array}{c}1.334 \\
(0.962)\end{array}$ & $\begin{array}{c}2.723 \\
(1.987)\end{array}$ \\
\hline Observations & 3,625 & 3,625 & 3,792 & 3,664 & 3,664 & 3,776 \\
\hline Adj. R-squared & 0.021 & 0.063 & 0.185 & 0.003 & 0.051 & 0.128 \\
\hline$F$-test on GP FE & - & - & $\begin{array}{c}F(218,3518)= \\
2.638 * * *\end{array}$ & - & - & $\begin{array}{c}F(243,3489)= \\
1.301 * * *\end{array}$ \\
\hline
\end{tabular}




\section{Table 8}

\section{Top and bottom quartile performance persistence}

This table presents the results from deal-level logit regressions of gross Public Market Equivalent (PME) binary quartile performance with the current deal $\left(\mathrm{n}_{0}\right)$ on binary quartile performance with the previous deal $\left(\mathrm{n}_{-1}\right)$. We use the three regional MSCI Performance Indices (Asia, Europe, North America) in local currency as benchmarks for our PME calculations and use the regional index where the GP is located. We only include fully realized unique deals for this analysis. In models (1) to (4) we use a top quartile dummy for the current deal as dependent variable and an equivalent one for the previous deal by the same GP as independent variable. Models (5) to (8) include equivalent bottom quartile dummies instead. For both performance quartiles, we also run separate regressions for the low and a high competition subsample. We use the sum of buyout funds raised in the three years prior to a given transaction, in the same region and industry divided by the GDP in the same (investment) year and region as proxy for competition. Hence, models (1), (2) report results for the top quartile dummies and the low competition subsample, models (3) and (4) for the high competition subsample and the same variables. Accordingly, models (5) and (6) show regression results using the bottom quartile dummies and the low competition subsample, models (7) and (8) for the high competition subsample. In models (1), (3), (5) and (7) we control for the $\log$ of deal sequence, the log of the equity investment size in million of USD, the log of the holding period in years, the $\log$ of fund age at investment date in years as well as investment year, industry and region fixed effects. Finally, models (2), (4), (6) and (8) display results from fixed effects regressions in which we add GP fixed effects but exclude lagged PME. The row at the bottom reports F-statistics from testing joint significance of the GP fixed effects in regressions (2), (4), (6) and (8). Standard errors are adjusted for serial correlation and heteroskedasticity and exhibited in parentheses. *, ** and *** denote statistical significance at the $10 \%, 5 \%$ and $1 \%$ levels respectively.

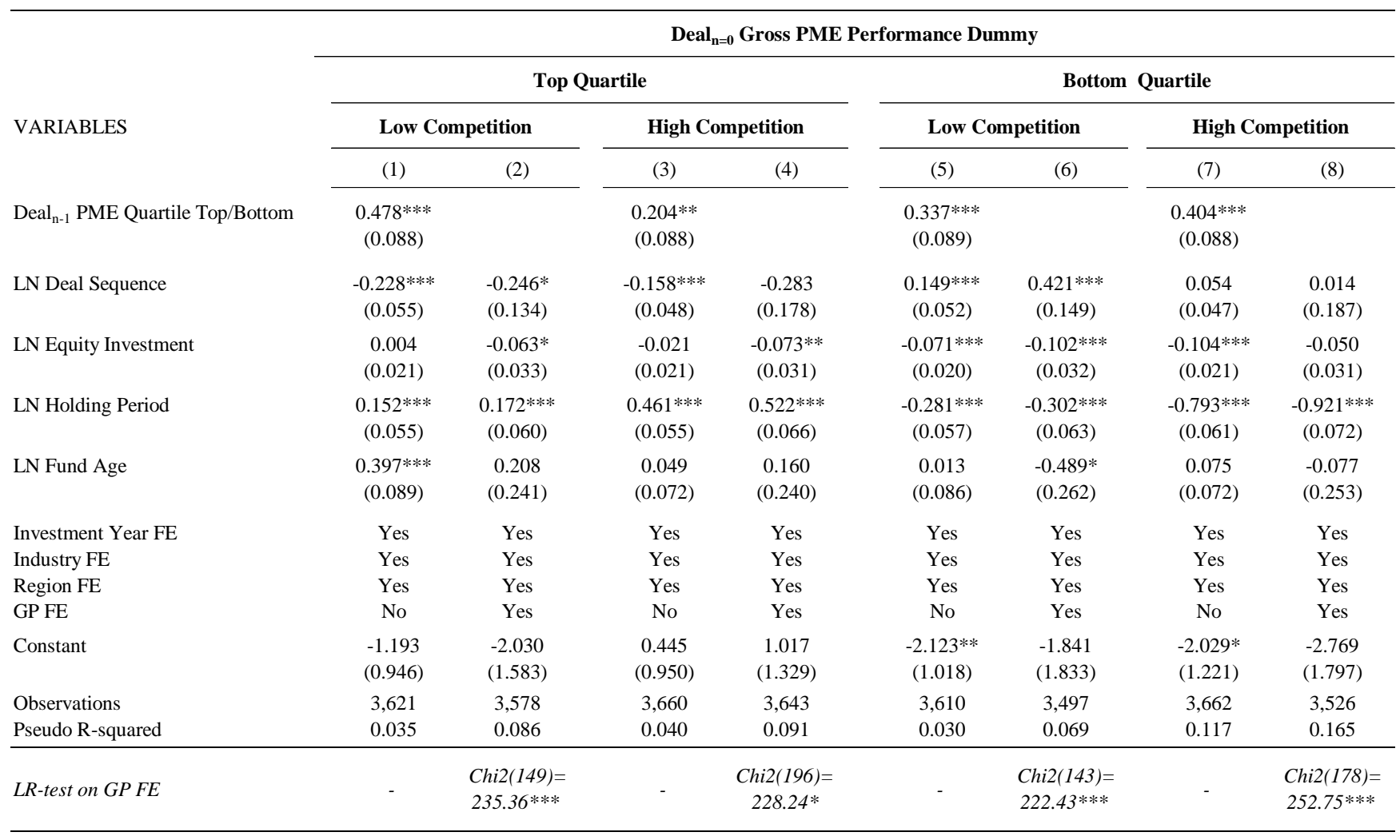




\section{Table 9}

\section{Long-term performance persistence}

This table presents the mean PME performance within deal performance quartiles, keeping the quartile groups for the 10 subsequent investments after a given deal by the same GP. To begin with, we put each deal in our sample into one of four performance quartiles based on its relative performance among all the deals in the same investment year. We compute mean PMEs (winsorized at the 99th percentile) for these four formation portfolios. This formation based on performance of deal $\mathrm{n}_{0}$ is kept for the ten following deals by the same GP. This means we put each next deal $\left(\mathrm{n}_{1}\right)$ into the same category as the formation deal $\left(\mathrm{n}_{0}\right)$ (irrespective of its own performance) and compute mean PMEs (winsorized at the 99th percentile) for these four portfolios of next deals. We repeat this procedure for all ten deals following deal $\mathrm{n}_{0}$ always using the formation set by deal $n_{0}$. For each group of following deals $n_{1}$ to $n_{10}$ we run a F-test to compare means across all quartiles, one onesided T-test comparing the top quartile deals' mean with all other quartiles, and another comparing the bottom quartile's mean with all other quartiles. The F- and T-values and the corresponding significance levels are reported below. *, ** and *** denote statistical significance at the $10 \%, 5 \%$ and $1 \%$ levels respectively. Panel A shows investments (and their subsequent deals by the same GP) done in low competition years. Panel B displays mean values for those deals $\mathrm{n}_{0}$ done in high competition years.

Panel A: Low Competition Formation Years

\begin{tabular}{|c|c|c|c|c|c|c|c|c|c|c|c|c|}
\hline \multirow{2}{*}{ Quartile $\mathbf{n}_{0}$} & \multirow[b]{2}{*}{ Obs. } & \multicolumn{11}{|c|}{ Mean Deal Gross PME } \\
\hline & & $\mathbf{n}_{0}$ & $\mathbf{n}_{1}$ & $\mathbf{n}_{2}$ & $\mathbf{n}_{3}$ & $\mathbf{n}_{4}$ & $\mathbf{n}_{5}$ & $\mathbf{n}_{6}$ & $\mathbf{n}_{7}$ & $\mathbf{n}_{8}$ & $\mathbf{n}_{9}$ & $\mathbf{n}_{10}$ \\
\hline 1 (Top) & 920 & 5.31 & 2.53 & 2.23 & 2.34 & 2.30 & 2.25 & 2.20 & 2.24 & 2.24 & 2.09 & 2.08 \\
\hline 2 & 983 & 1.82 & 2.04 & 1.98 & 1.97 & 1.91 & 1.96 & 1.88 & 1.94 & 1.92 & 1.96 & 2.10 \\
\hline 3 & 976 & 0.89 & 1.73 & 1.74 & 1.78 & 1.81 & 1.92 & 1.95 & 1.97 & 1.76 & 1.96 & 1.81 \\
\hline 4 (Bottom) & 913 & 0.15 & 1.61 & 1.90 & 1.83 & 1.77 & 1.71 & 1.82 & 1.67 & 1.81 & 1.85 & 1.73 \\
\hline Total & 3,792 & 2.01 & 1.97 & 1.96 & 1.97 & 1.94 & 1.96 & 1.96 & 1.95 & 1.93 & 1.96 & 1.93 \\
\hline$\underline{F \text { test }}$ & & $1344.8 * * *$ & $22.10 * * *$ & $5.28 * * *$ & $7.98 * * *$ & $7.29 * * *$ & $5.97 * * *$ & $3.07^{* *}$ & $6.50 * * *$ & $5.47 * * *$ & 0.99 & 4.17 *** \\
\hline \multicolumn{13}{|l|}{$T$ test } \\
\hline Top vs. $2-4$ & & $-57.8 * * *$ & -7.30 *** & $-3.44 * * *$ & $-4.63 * * *$ & $-4.54 * * *$ & $-3.67 * * *$ & $-2.85 * * *$ & $-3.58 * * *$ & $-3.84 * * *$ & $-1.48 *$ & $-1.90 * *$ \\
\hline Bottom vs $1-3$ & & $26.0 * * *$ & 4.66 *** & 0.74 & $1.86^{* *}$ & $2.21^{* *}$ & $3.15 * * *$ & $1.74^{* *}$ & $3.57 * * *$ & $1.48 *$ & $1.32 *$ & $2.46^{* * *}$ \\
\hline
\end{tabular}

Panel B: High Competition Formation Years

\begin{tabular}{|c|c|c|c|c|c|c|c|c|c|c|c|c|}
\hline \multirow{2}{*}{ Quartile $\mathbf{n}_{0}$} & \multirow[b]{2}{*}{ Obs. } & \multicolumn{11}{|c|}{ Mean Deal Gross PME } \\
\hline & & $\mathbf{n}_{0}$ & $n_{1}$ & $\mathbf{n}_{2}$ & $\mathbf{n}_{3}$ & $\mathbf{n}_{4}$ & $\mathbf{n}_{5}$ & $n_{6}$ & $\mathbf{n}_{7}$ & $\mathbf{n}_{8}$ & $\mathbf{n}_{9}$ & $\mathbf{n}_{10}$ \\
\hline 1 (Top) & 987 & 5.34 & 2.37 & 2.29 & 2.46 & 2.22 & 2.11 & 2.22 & 2.14 & 2.17 & 2.20 & 2.00 \\
\hline 2 & 905 & 2.07 & 2.33 & 2.14 & 2.05 & 2.03 & 2.08 & 2.24 & 2.20 & 2.12 & 2.20 & 2.12 \\
\hline 3 & 922 & 0.95 & 1.94 & 2.06 & 1.98 & 2.15 & 2.06 & 1.93 & 1.97 & 1.99 & 1.89 & 1.89 \\
\hline 4 (Bottom) & 962 & 0.12 & 1.89 & 1.96 & 1.90 & 2.08 & 2.13 & 1.95 & 1.91 & 1.96 & 1.76 & 2.06 \\
\hline Total & 3,776 & 2.13 & 2.13 & 2.11 & 2.10 & 2.12 & 2.09 & 2.08 & 2.05 & 2.06 & 2.01 & 2.02 \\
\hline$\underline{F \text { test }}$ & & $1654.9^{* * *}$ & 8.09 *** & $2.38 *$ & 7.23 *** & 0.70 & 0.10 & 2.81 & 1.76 & 0.93 & $4.44 * * *$ & 0.79 \\
\hline \multicolumn{13}{|l|}{$\underline{T}$ test } \\
\hline Top vs. $2-4$ & & $-61.5 * * *$ & $-3.12 * * *$ & $-2.27 * *$ & $-4.50 * * *$ & -1.15 & -0.13 & $-1.58 *$ & -0.95 & -1.24 & $-2.03 * *$ & 0.19 \\
\hline Bottom vs 1-3 & & $30.8 * * *$ & 3.22 *** & $1.97^{* *}$ & $2.53 * * *$ & 0.46 & -0.43 & $1.59 *$ & $1.68 * *$ & 1.12 & $2.80 * * *$ & -0.45 \\
\hline
\end{tabular}

